Article

\title{
Creating Smart Energy Cities for Sustainability through Project Implementation: A Case Study of Bolzano, Italy
}

\author{
Garfield Wayne Hunter ${ }^{1, *(1)}$, Daniele Vettorato ${ }^{2}$ and Gideon Sagoe ${ }^{3}$ (i) \\ College of Architecture and Urban Planning, Tongji University, Shanghai 200092, China \\ Institute of Renewable Energy, EURAC Research, 39100 Bolzano, Italy; daniele.vettorato@eurac.edu \\ Sewerage Systems Ghana Ltd., P.O. Box GP 1630, Accra, Ghana; sagoe_ugms@yahoo.com \\ * Correspondence: garfield.hunter@tongji.edu.cn
}

Received: 26 May 2018; Accepted: 20 June 2018; Published: 25 June 2018

\begin{abstract}
Globally, cities are experiencing an unprecedented socio-economic, demographic, and environmental transition that brings with it negative environmental externalities, such as climate change and environmental degradation. Smart energy city (SEC) has emerged as the latest urban development strategy in European countries. It can vastly accelerate cities' decarbonisation efforts, which can have several co-benefits. Capitalising on advances in information and communication technologies (ICT), various SEC projects have been initiated and seek to integrate ICT into the urban system. Although there are a significant number of SEC demonstration projects, there has been a scant examination of the performance and overall effect of these projects in addressing core sustainability endogenous principles. This research provides an in-depth analysis of the components of the SEC projects, highlighting the strengths and shortcomings. By highlighting the "Smart INitiative of cities Fully cOmmitted to iNvest In Advanced large-scale energy solutions" (SINFONIA) project in Bolzano, we aimed to determine the extent to which the current practical processes are achieved in reality. Our methodology entailed a structured literature review of the different components of SEC projects, followed by a content analysis based on the $5 \mathrm{~W} 1 \mathrm{H}$ (why, what, who, how, where, and when) conceptual framework. The data collection methods adopted included a review of specific open-access sources and project deliverables of each of the selected SEC projects, personal observation of the case study city, and interviews with SEC project experts. We analysed the SEC projects components against fundamental sustainability principles of integration, implementation, equity (intra-generational, procedural, and inter-generational), and scalability and replicability to assess their potential for creating sustainable urban settlements. The study found that the critical components of SEC projects are strategically aligned with sustainability dimensions. However, although ICT integration in urban planning and development provides the core determinants of the components, stakeholder engagement and dynamic business models are critical for successful implementation. Furthermore, through scalability and replicability of SEC projects, diversification of sustainability principles can be actualised throughout the entire city and in other geographical regions to ensure long-term intra-generational and inter-generational equity.
\end{abstract}

Keywords: smart energy city; smart city; project planning; implementation; urban development; ICT; sustainability

\section{Introduction}

Historically, cities have been the engines of societies. They are the nucleus of innovation, hubs of decision-making power, and centres of economic growth and modernisation. They typically 
have unique characteristics and access to modern lifestyle and infrastructures. However, cities are simultaneously experiencing unprecedented socio-economic, demographic, and environmental transitions that cause negative environmental externalities, such as climate change, energy insecurity, and environmental degradation. Analogous to global trends, Europe is predominantly urbanised, with approximately $72.6 \%$ of the population residing and working in urban areas [1], which is estimated to increase to $82 \%$ by 2050 [2]. According to Eurostat, 2016 [1], in 2012 urban regions in EU-28 generated approximately $53 \%$ of the gross domestic product (GDP); however, in 2014, approximately 34 million urban dwellers were living in poverty and social exclusion [1]. Moreover, European cities consume between $60-80 \%$ of the energy and emit as much greenhouse gas (GHG) emissions [3]. These urbanisation trajectories will create unparalleled sustainability challenges and have the potential to disrupt the urban system.

Faced with the challenge of securing high quality of life for citizens through healthy and liveable communities, cities play a crucial role in the transition to a sustainable, low-carbon economy, while becoming more energy efficient [4]. As a proactive response, urban decision-makers and urban planners have redesigned their city planning strategies to incorporate integrated urban development models to direct the future growth of cities and address urban sustainability challenges. Chief among them are sustainable cities, eco-districts, eco-cities, resilient cities, digital cities, virtual cities/information cities, knowledge-based cities, intelligent cities, low-carbon cities, low carbon eco-cities, smart cities, ubiquitous cities, and smart energy cities [5]. Irrespective of the adopted contemporary urban configuration, based on city context and vision of urban development, city planning should address core sustainability issues of integration, implementation, equity, scalability, and replicability [6].

Practically, smart energy city (SEC) has emerged as the latest incarnation of urban planning and development strategies adopted by European cities as a core pillar of the smart city [7]. These SECs promote continuous transformative processes based on carbon neutrality, optimised renewable energy utilisation, institutional and technical capacities, economic efficiency, and stakeholder engagement and awareness. SECs are anchored on Information and Communication Technology (ICT) to enhance quality of life and enable complex systems to become efficient. In this regard, the concept has become a lynchpin approach that collectively connects energy reduction, sustainability, and innovation, while enabling cities to overcome the shortcomings of traditional urbanisation models that manage urban development in silos [4]. Even though no universally accepted definition of SEC exists, substantial work is continuing apace towards an applied model for planning and implementation. One of the first attempts to demystify the SEC concept was put forward by Nielsen et al. 2013 [8]. Their research highlights the need to coalesce an energy system with physical planning anchored on ICT and behavioural attributes. The definition clarifies the conceptual construct and explains four fundamental principles that encompass SEC. These include energy and resource efficiency, renewable energy sources, integrated and resilient resource systems, and ICT. Later, Mosannenzadeh et al. 2017 [9] expanded this characterisation and developed a theoretical definition of SEC, highlighting the principles, domains of intervention, stakeholders, and practical solutions. They define an SEC project as "one that aims at the sustainability of energy systems and services through the optimised integration of increased energy conservation, energy efficiency and use of local renewable energy sources. SEC projects have a specific period; they apply smart energy solutions to integrate multiple energy domains, and enforce collaboration of multiple stakeholders while evaluating the sustainability of their measurements." Both studies emphasise that SEC is focal to the smart city development model and intersects with the principles of sustainability. For this reason, reference and benchmark campaigns such as the Green Digital Charter (GDC), launched in 2009 [10], provide a strategic framework for European cities to commit and utilise ICT as the main catalysing driving force for achieving sustainability targets and greening ICT to create low carbon societies.

On the global front, a review of the international smart city approach and the intrinsic semantics associated with SEC reveals that the strategic framework to commit and utilise ICT has only progressed 
partially. This is because the solutions are centred around smart energy technologies such as smart grid; smart metering; smart district heating; and cooling systems, waste, and water. The scale of development, the ICT solutions, and the process of development can vary significantly given the existing paradigm of the urban milieu. However, the development of SEC within smart cities encompasses two different development trajectories: Brownfield and Greenfield transformation [11]. Even though the functional paradigm has failed or stalled in some development projects, some practical international case studies exist.

The Brownfield projects incorporate retrofitting or renewal of existing urban systems and neighbourhoods to facilitate the introduction of ICT. This development process occurs incrementally, converging on priority urban issues and having a short-term time horizon. International Brownfield SEC projects aim to achieve an energy-efficient retrofit of buildings, sustainable urban transportation, and mobility; the redevelopment of existing infrastructures; and the regeneration of existing greyfield neighbourhoods. In China, Shanghai has formulated a smart city plan, with the goals being globalisation, informatisation, and modernisation that generates "innovation-driven transformation" using a top-down approach [12]. Supported by central government guideline notifications "Notice to Speed up the Project Implementation of Smart Cities (2014)", "National New Urbanisation Plan (2014-2020)", and "Guidance on Promoting the Sustainable Development of Smart Cities (2014)", the city pursues cutting-edge technologies in an effort enhance urban services. SEC interventions within the smart city plan integrate smart electricity grid technologies such as smart metering, energy management systems, smart district heating and cooling, and waste and water management. Meanwhile, in Guadalajara, Mexico, the Creative Digital City "living lab" project uses a comprehensive master plan to rehabilitate an existing historic district in the city through the extensive use of technological innovation to improve quality of life and spur economic growth [13]. Entrenched in this redevelopment is the use of integrated urban planning with SEC strategies leading to digital and sustainable environment, such as smart grid, smart solid waste systems, electric vehicle charging stations, smart sanitation, energy efficient and LEED-certified green buildings, LED lighting, intelligent traffic management, energy storage, integrated multi-modal transportation system, photovoltaic and solar thermal, smart parking, smart points, and a hub and microgrid data center.

The Greenfield SEC projects are part of urban extension smart city pilot or demonstration projects, requiring more considerable ICT investments for the development of the urban system from scratch. They are strategically located and constructed, based on long-term master or development plans that integrate comprehensive physical development with ICT infrastructures. As a result, these projects have extended land use planning based on compact and mixed-use development patterns, aiming to augment the proposed smart cities efforts. In South Korea, the Songdo international business district (IDB) smart city was designed and constructed based on the LEED-ND principles [14] to provide sophisticated technologies to optimise the operational efficiency of the city. The SEC solutions that have been incorporated into this development include smart energy management and the monitoring of green and energy-efficient buildings to monitor and provide feedback on energy use and controlled building services, smart bike services, e-vehicles and charging stations, smart waste management systems, and environmental detection sensors for carbon emissions monitoring. Also, Masdar smart city is being built on carbon neutrality principles to stimulate economic development through the optimisation of resource and clean energy technologies [15]. Designed as a living lab/experimentation, the city's energy system will be fulfilled through the utilisation of renewable energy technologies such as photovoltaic, solar thermal, wind, and desalination, and in the meanwhile, carbon emissions and resource consumption will be reduced through energy efficiency in water and building consumption. This includes smart and sustainable mobility such as car-free landscape, bike-sharing stations, and smart driverless shuttles.

More recently, several scholars have suggested that the deployment of SEC solutions, in which multiple domains of interventions are integrated into the development projects, can enable cities to achieve EU sustainability (climate and energy) targets [16-18]. SECs hinge on the European 
Union's crosscutting binding climate and energy policies that transcend climate change and energy security [19]. For this reason, the concept has gained increasing attention from scholars and sustainability professionals, as it is aligned to the binding 2020 targets for the reduction of GHG emission $(20 \%)$, increased utilisation of renewable energy (20\%), and improvements in energy efficiency $(20 \%)$ [1]. Furthermore, other sustainability policies such as the 2050 low-carbon roadmap [20], the EU Transport White Paper [21], the EU energy efficiency policy [22], and the European Energy Security Strategy [23] have established hard-headed strategies to promote sustainable urban development.

Experts increasingly recognise the vital role of smart cities in engendering an extensive array of triple-bottom-line benefits that both the public and policymakers acknowledge and aspire to attain. As a result, the European Commission (EC) has established strategic and operational orientations towards the implementation of smart cities [19]. The integrated Strategic Energy Technology (SET) Plan [24] is the central decision-making tool that accelerates the development and deployment of low carbon energy technological pathways for climate and energy strategies and research and innovation priorities in the EU. The European Innovation Partnership on Smart Cities and Communities (EIP-SCC) provides the guiding framework for the development of SEC projects in EU smart cities and communities platform. This platform delivers mobilising and operational guidelines using the strategic implementation plan (SIP) [25] and operational implementation plan (OIP) [26]. These are used for the formulation of action clusters (focusing on integration), large-scale demo projects, stakeholder relationships, funding for demonstration and market uptake through new business models, and legislative and non-legislative strands [18].

This has resulted in several ambitious, replicable, and participatory SEC projects that support an integrated approach to energy planning and project development [27]. Such projects have the opportunity to potentially improve the quality of life and the quality of urban services $[9,28]$. By adopting an integrated approach, the SEC project can achieve more holistic solutions to complex problems by bringing together different kinds of stakeholders, sectors, and technologies, and incorporating the dimension of sustainability.

Although there is a vast number of SEC demonstration projects [27,29], there has been a scant examination of the performance and overall effect of these projects in addressing core sustainable principles. The quest for sustainable urban development is recognised as the central aim of cities [6]. As Basiri et al. [30] state, "sustainable development in each characteristic of the Smart City Model, should always be examined through a lens of the Sustainability Principles," however, "Smart cities highlight important aspects of sustainability, such as the need for responsible resource management, energy efficiency, and citizen engagement." Previous studies such as Bisello, et al. [27] analysed 36 smart and sustainable energy district projects to identify and develop a taxonomy of co-benefits smart at a district level. Meanwhile, the authors of [31] identified and prioritised 35 barriers that hinder the implementation of SEC projects in 43 communities. However, there is an empirical gap in the literature to assess if current SEC projects contribute to actual sustainable development.

Accordingly, utilising the above body of studies and guidelines as the starting point, this research sought to analyse 27 SEC projects in the European Union (EU) Smart Cities Information System (SCIS) platform that address interventions in an integrated multi-disciplinary approach on how to create and implement a smart city. That said, the primary purpose of this research is to fill the gap in the literature regarding the SEC projects and their success in enhancing the sustainability of urban settlements. With this in mind, we utilised the $5 \mathrm{~W} 1 \mathrm{H}$ approach to deconstruct SEC projects to identify objectives, domains, implementation approach, stakeholders, time horizon, and scale. We then assimilated and analysed these components based on four sustainability principles of integration, implementing, equity, and scalability and replicability. This was then applied through a case study in the city of Bolzano to inform the study empirically. As a result, the specific aims were (1) to identify the main components of SEC projects in the EIP-SCC, (2) to analyse the extent to which the various components of SEC projects have assimilated the core principles of sustainability, (3) to determine if the current components are 
achievable in reality using SINFONIA project, and (4) to conclude if the current SEC models can be juxtaposed in other regions.

We organised the paper as follows. Section one presents a contextual background of the study. Section two presents the materials and methods. The third section presents the findings and discussion from the analysis of SEC projects. Section four presents an analysis of the city of Bolzano implementation of the SINFONIA project as a case study. In section five, we provide a synthesis of the paper based on our primary aims.

\section{Materials and Methods}

This was primarily an empirical research study, with data collected based on open access sources and project deliverables of each of the selected SEC projects, participant observation of the case study city, and informal interviews with SEC project experts. We accessed the official web pages of the SEC projects between April and December 2017 (see Table A1). The websites are open source depositories and communication channels for SEC projects, providing detailed information on inputs, processes, and outputs. Project deliverables, other SEC web databases (EU SCIS-https: //smartcities.info.system.eu/projects the marketplace of the EIP SCC—https://eu-smartcities.eu/3, Community Research and Development Information Service (CORDIS)—https://cordis.europa.eu/), and specific project websites were investigated. Our search strategy mirrors that utilised by [28]. We considered projects that have taken a holistic approach (covering technical and non-technical solutions) to SEC development based on the EIP-SCC initiative and the SIP Plan: smart building retrofit, energy and technologies, transport and mobility, and supporting ICT and integrative infrastructure solutions. Therefore, only SEC projects that incorporate three or more strands were included. Based on these criteria, we identified and selected 27 European projects (see projects reviewed in Figure 1 and projects locations in Figure 2) that mainly straddle the EU's Seventh Framework Programme (FP7) and the Horizon 2020 (European Union research and development funding programme).

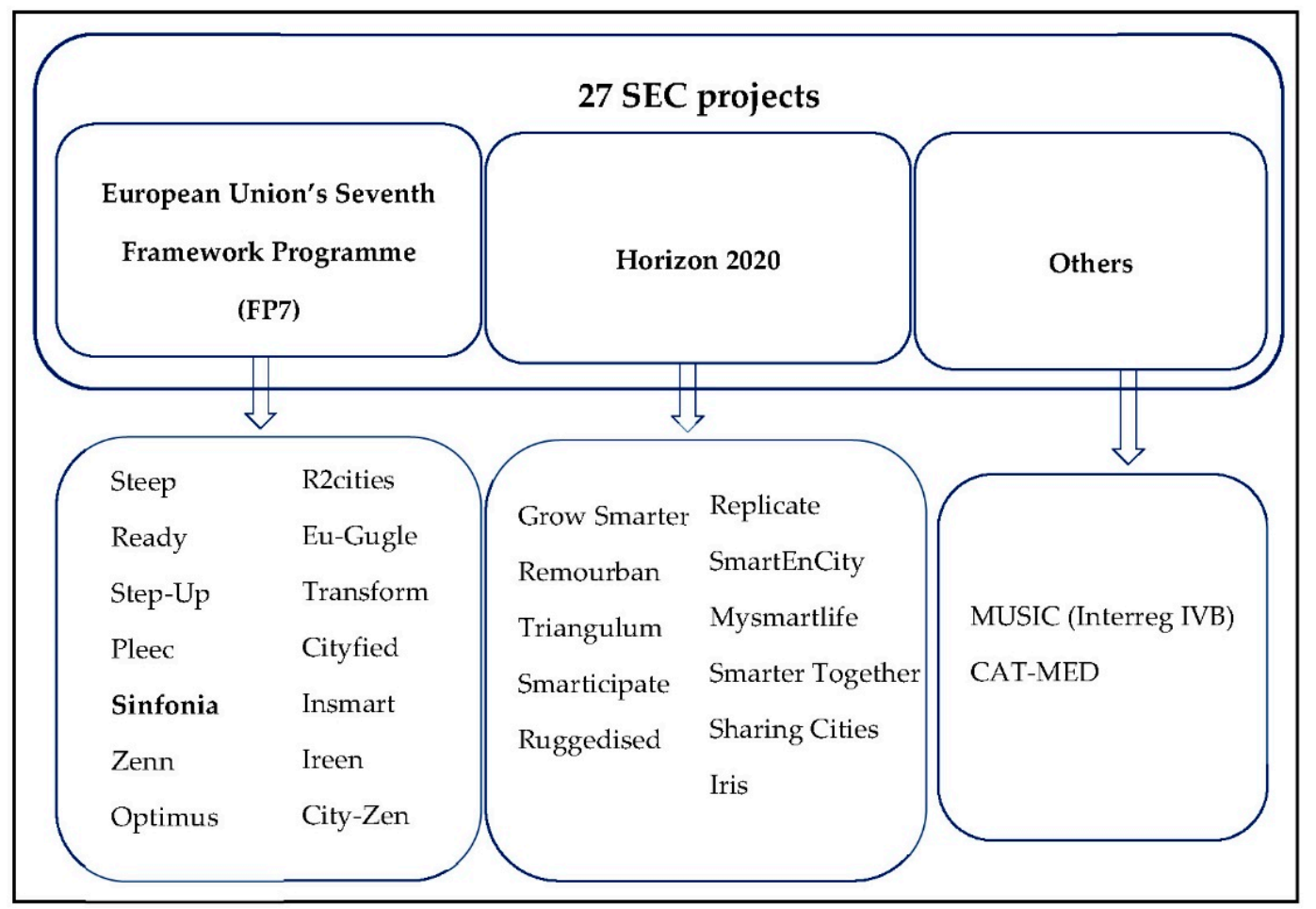

Figure 1. Smart energy city projects reviewed. 


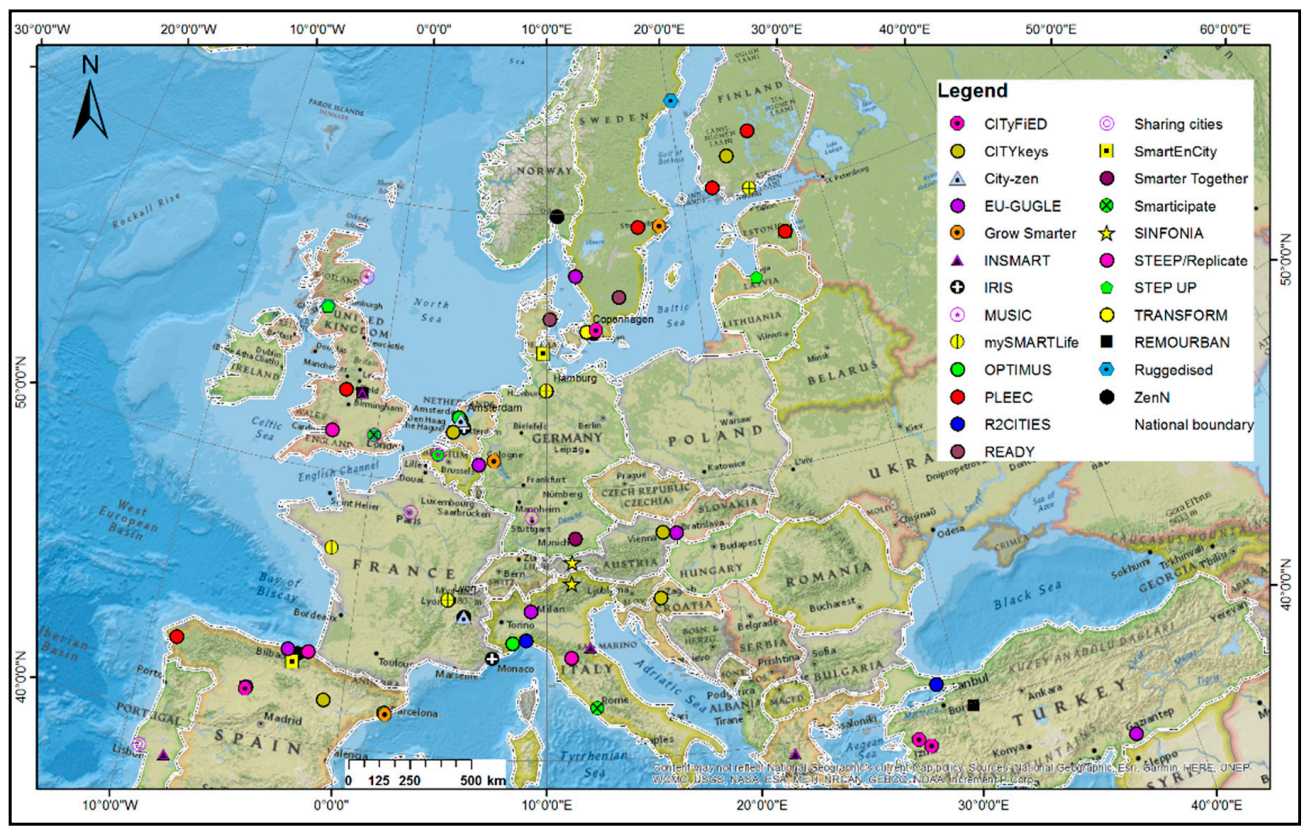

Figure 2. Locations of the SEC projects.

To gather information from the each SEC project, we used content analysis based on the $5 \mathrm{~W} 1 \mathrm{H}$ Kipling method [32]: why, what, who, where, and when (time horizon), to analyse and evaluate the components of SEC projects (see Table 1). The primary indicators assessed include (1) "why" establishes the rationale for the initiative and which dimensions it contributes, e.g., environment, social, economic, and governance; (2) "what" details the main planning domains of the intervention of SEC solutions, e.g., buildings, transportation, ICT and integrated infrastructures, and energy and technology; (3) "how" describes how the plan was implemented using various tools and mechanisms, e.g., governance, planning mechanisms, monitoring and evaluation, funding, and context and process; (4) "who" includes information about the institution and its partners responsible for conducting the initiative, e.g., decisionmakers, experts, utilities, end-users, community organisations, financial institutions, and the private sector; (5) "where" includes information on the scale of the development, e.g., individuals, buildings, neighbourhoods, districts, cities, transportation; (6) "when" describes the time horizon for the implementation of the projects, e.g., short, medium, and long-term. The Kipling approach was selected, as it provides a systematic approach to problem-solving and project planning for information gathering and deconstructing the literature [33]. Content analysis is a widely utilised scientific approach for the empirical and structured analysis of documents and communications [34], which is then examined, classified, and summarised.

To compare the dominance of a sub-criterion (e.g., specific objective, planning domain, or implementing aspect) concerning all other sub-criteria considered in the SEC projects, we calculated its relative weight $\left(w_{r}\right)$ using the expression

$$
w_{r}=\frac{x_{i}}{\sum_{i=1}^{n} x_{i}}
$$

in which $x_{i}$ is the percentage score of sub-criterion and $+n$ is the total number of sub-criteria. The relative weight of a main criterion was calculated as the sum of the relative weights of its sub-criteria.

To assess the sustainability of SEC projects, we analysed the components against the four core endogenous sustainable development principles (see Table 1), which include integration, implementation, equity (procedural, intra-generational, and inter-generational), and scalability and replicability $[6,35,36]$. 
Table 1. A methodological approach based on Kipling $5 \mathrm{~W} 1 \mathrm{H}$ conceptual framework and the main endogenous sustainability assessment dimensions.

\begin{tabular}{|c|c|c|c|c|c|c|c|}
\hline \multirow[t]{3}{*}{ Questions } & \multirow[t]{3}{*}{ Main Strands } & \multicolumn{6}{|c|}{$\begin{array}{c}\text { Endogenous Sustainability Assessment } \\
\text { Principles }\end{array}$} \\
\hline & & \multirow[t]{2}{*}{ A } & \multirow[t]{2}{*}{ B } & \multicolumn{3}{|c|}{$\mathrm{C}$} & \multirow[t]{2}{*}{$\mathrm{D}$} \\
\hline & & & & I & II & III & \\
\hline Why develop an SEC? & Objectives & $\sqrt{ }$ & \multirow{6}{*}{$\sqrt{ }$} & & \multirow{6}{*}{$\sqrt{ }$} & & \\
\hline What are the components of SEC? & Planning & $\sqrt{ }$ & & & & $\sqrt{ }$ & \\
\hline How are SEC Implemented? & Implementation & & & & & & \\
\hline Who are the stakeholders involved in creating SEC? & Stakeholders & & & & & & \\
\hline Where to implement SEC? & Scale & & & & & & $\sqrt{ }$ \\
\hline When to implement SEC? & Time horizon & & & $\sqrt{ }$ & & & \\
\hline
\end{tabular}

Following this, we analysed the case study area to investigate, in detail, the essential components and sustainable principles that are being implemented in real-life context to gain a more reliable understanding of the complexity surrounding SEC projects and their aim to create more sustainable communities. We utilised case study participant observation approach to collating data to examine the implementation of the SINFONIA project in Bolzano. This entailed informal interviews with SEC project personnel, direct observation, and review of technical reports (project deliverables).

\section{Results and Discussion}

This section provides a detailed analysis of the SEC projects components, analysed against the four sustainable principles: integration, implementation, equity (intra-generational, procedural and inter-generational), and scalability and replicability.

\subsection{Integration}

The integration principle of sustainability indicates that SEC projects require balanced assimilation of the core interconnected dimensions of sustainability (social economic, environmental, and governance) [6]. It is pivotal that the essential co-benefits that result from the implementation of the individual SEC solutions in the domains of intervention are identified, and their interdependencies are integrated to maximise holistic benefits to the community.

In European cities, challenges such as climate change, energy security, resource scarcity, GHG emission, and urbanisation threaten the quality of life and the overall sustainability of citizens. However, these cities also act as the catalysts for socioeconomic development, inclusive governance, and infrastructural growth. These are the fundamental drivers that necessitate the development of SEC projects in cities. Therefore, the primary aim of SEC projects is creating liveable cities, which integrates ICT technologies within multiple urban system domains to ensure transformational impacts and to improve the quality of living within a particular timeframe and with available resources [37]. The objectives are thus an indispensable starting point for action and define the direction of efforts throughout cities to achieve a sustainable society. The essential objectives underpinning the development of SEC projects can succeed and propagate over time if they are intertwined within the broader dimensions of sustainable development. Based on the SEC projects, we deconstructed 13 specific objectives, which encapsulate under environmental, economic, social, and governance aspects, and the results are presented in Figure 3.

The environmental objectives describe the overall aims that a project establishes to tackle or lessen environmental externalities and improve environmental quality continually. They aim to reconcile the city's role as a liveable city while reducing its carbon footprint. They include reducing GHG emissions, reducing energy use, increasing renewable energy, improving urban mobility, and improving energy efficiency. The results showed that improving energy efficiency and reducing energy usage and GHG 
emissions are paramount in the SEC projects: all the projects reviewed sought to reduce both energy use and GHG emissions. About $82 \%$ incorporated strategies to improve urban mobility, whereas $74 \%$ targeted increased renewable energy.

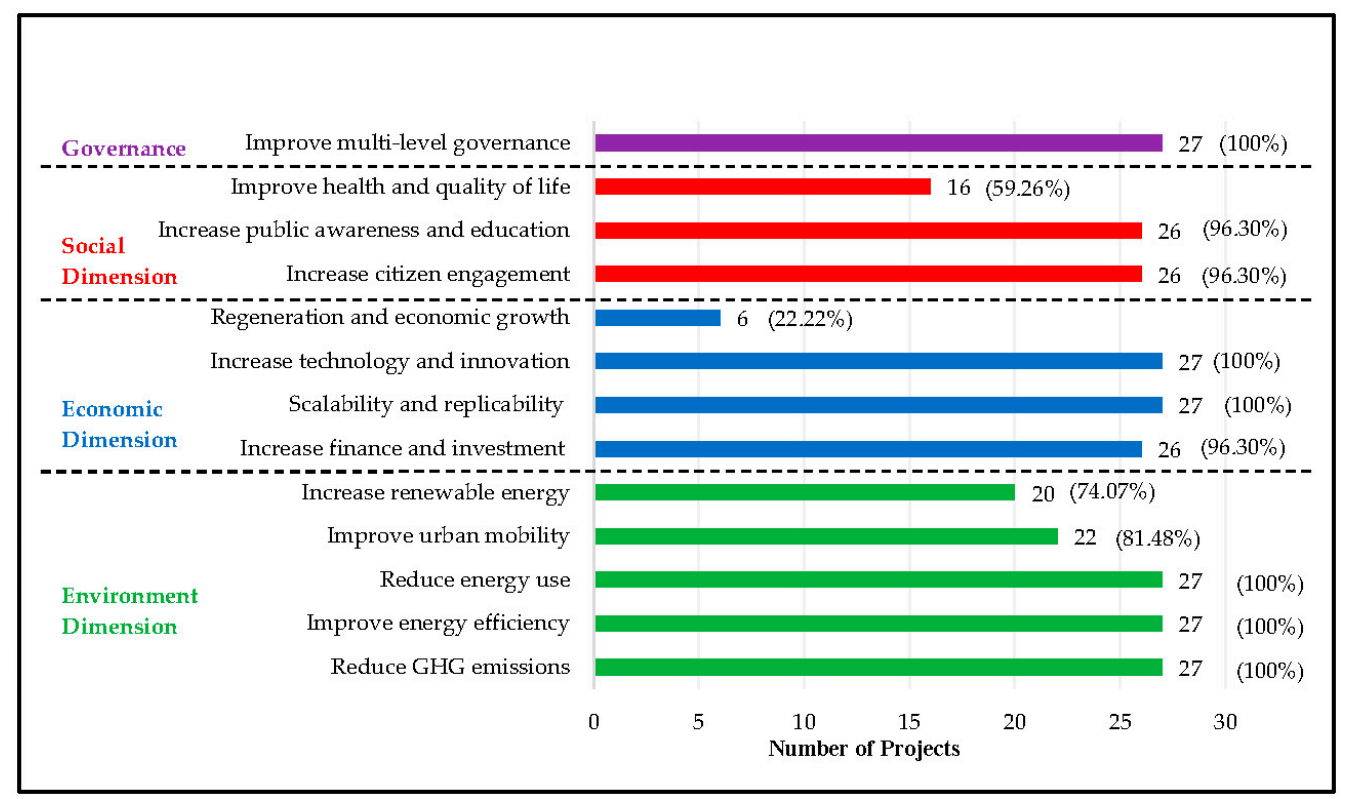

Figure 3. Specific objectives of SEC projects structures within sustainability dimensions.

Economic objectives aim to stimulate inclusive local economic development with a transition from traditional economic structures to smart and innovative technology. This can be achieved by harnessing creativity; coalescing with scientific research, environmentally friendly production, resource efficiency; and generating opportunities for improving competitiveness. To achieve the desired economic impacts, the chief economic objectives include increased regeneration and economic growth, increased technology and innovation, scalability and replicability, and increased finance and investment. Apart from the objective of regeneration and economic growth, which was identified in only $23 \%$ of the projects studied, the other three were integrated into all the projects.

The social objectives aim to establish and reconcile a society for human interaction and general well-being through the involvement of communities in the process of innovation, communication, and cultural development to improve health and quality of life, foster citizen engagement, and increase public awareness and education. The results showed that all the 27 projects featured both the objectives of increasing public awareness and education, and also increasing the involvement of the public, while about $59 \%$ included the objective of improving health and quality of life.

The governance objective entails recalibrating the traditional institutional and regulatory environment by cogently utilising its internal and external resources for making consistent and pragmatic decisions relevant to structuring complex public problems. The governance objective of SEC projects is to improve multi-level governance to enhance open-access, accountable, inter-institutional collaboration and cooperation, and participation through the assignment of responsibilities and improving capacity [38-40]. From the results (Figure 2), all the projects included the element of improving multi-level governance.

Considering all the 27 SEC projects, relative to other project objectives, the environmental ( $40.5 \%)$ aspect covered a more substantial portion of the entire project objectives considered, followed by the economic dimension (28.3\%), the social aspect $(22.4 \%)$, and the aspect of governance $(8.9 \%)$ as shown in Table 2. 
Table 2. Relative proportions of objectives concerning all project objectives.

\begin{tabular}{clcc}
\hline Objective & \multicolumn{1}{c}{ Specific-Objectives } & $\begin{array}{c}\text { Relative Weight of } \\
\text { Specific Objective }\end{array}$ & $\begin{array}{c}\text { Relative Weight } \\
\text { of Objective }\end{array}$ \\
\hline \multirow{2}{*}{ Governance } & Improve multi-level governance & $0.089(8.9 \%)$ & $0.089(8.9 \%)$ \\
\hline \multirow{2}{*}{ Social } & Improve health and quality of life & $0.053(5.3 \%)$ & \\
& Increase public awareness and education & $0.086(8.6 \%)$ & $0.224(22.4 \%)$ \\
& Increasing citizen engagement & $0.086(8.6 \%)$ & \\
\hline \multirow{2}{*}{ Economic } & Regeneration and economic growth & $0.020(2.0 \%)$ & \\
& Increase technology and innovation & $0.089(8.9 \%)$ & $0.283(28.3 \%)$ \\
& Scalability and replicability & $0.089(8.9 \%)$ & \\
& Increase finance and investment & $0.086(8.6 \%)$ & \\
\multirow{2}{*}{ Environmental } & Increase renewable energy & $0.066(6.6 \%)$ & \\
& Improving urban mobility & $0.072(7.2 \%)$ & $0.405(40.5 \%)$ \\
& Reduce energy use & $0.089(8.9 \%)$ & \\
& Improve energy efficiency & $0.089(8.9 \%)$ & \\
& Reduce GHG emissions & $0.089(8.9 \%)$ & \\
\hline
\end{tabular}

The domains of SEC projects are the essential priority areas and the integrated alternative solutions [9]. Therefore, in-keeping with operational approach utilised in $[9,24,41]$ to demarcate domains, we found that transportation and mobility (included in $85 \%$ of the projects), energy and technology (included in all or 100\% of the projects), buildings (included in all the projects), and ICT and integrated infrastructure (included in all the projects) are the four principal domains covered in all SEC projects (see Figure 4). Achieving sustainability will require significant and widespread changes in human behaviour [30]. The central planning themes constituted about $75 \%$ of the planning domains, whereas the remainder represented the domains of other planning themes (Table 3).

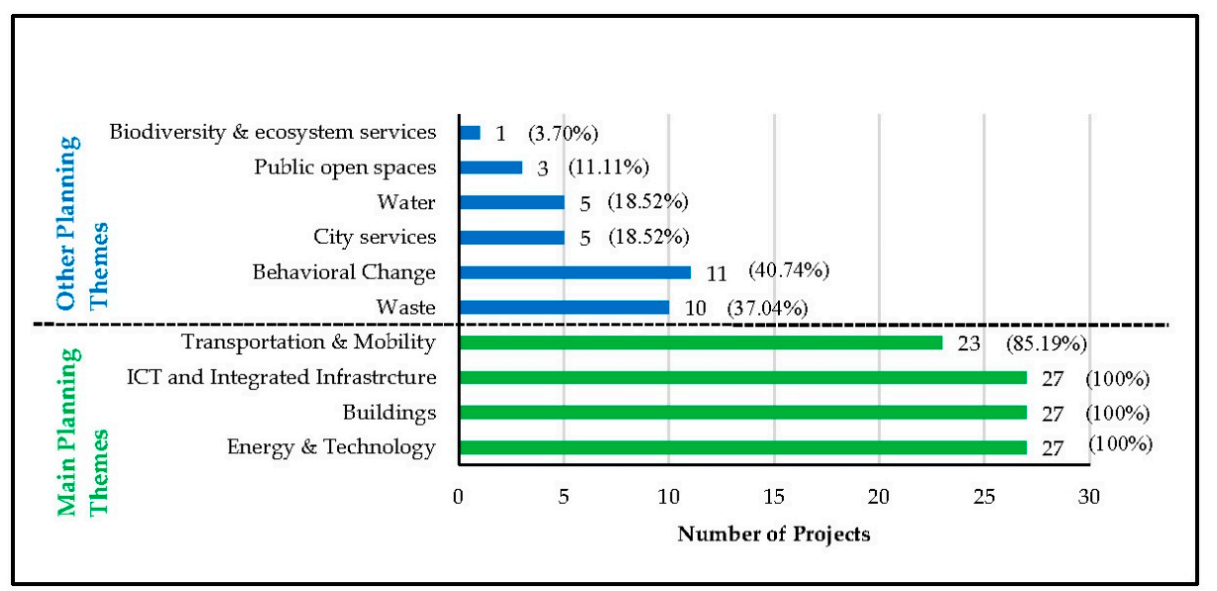

Figure 4. Distribution SEC project domain of intervention.

Table 3. Relative proportions of the planning elements.

\begin{tabular}{clcc}
\hline Planning Theme & \multicolumn{1}{c}{ Planning Domain } & $\begin{array}{c}\text { Relative Weight of } \\
\text { Planning Domain }\end{array}$ & $\begin{array}{c}\text { Relative Weight of } \\
\text { Planning Theme }\end{array}$ \\
\hline \multirow{5}{*}{ Main } & Transportation and mobility & $0.165(16.5 \%)$ & \\
& ICT and integrated infrastructure & $0.194(19.4 \%)$ & $0.748(74.8 \%)$ \\
& Buildings & $0.194(19.4 \%)$ & \\
& Energy \& Technology & $0.194(19.4 \%)$ & \\
\hline \multirow{5}{*}{ Other } & Biodiversity and ecosystem services & $0.007(0.7 \%)$ & \\
& Public open spaces & $0.022(2.2 \%)$ & \\
& Water & $0.036(3.6 \%)$ & $0.252(25.2 \%)$ \\
& City services & $0.036(3.6 \%)$ & \\
& Behavioural change & $0.079(7.9 \%)$ & \\
& Waste & $0.072(7.2 \%)$ & \\
\hline
\end{tabular}


In EU countries, the building industry accounts for $40 \%$ of the final energy consumption and $36 \%$ of carbon emissions [42]. The European Environmental Agency's (EEA) GHG inventory for 2017, highlights that the GHG emissions from buildings are one of the chief driving forces for the increase of the EU's GHG emissions by $0.5 \%$ in 2015 (compared to 2014) [42]. Additionally, given that $35 \%$ of buildings in member states are 50 years or older, the EC has elaborated numerous directives (2009/28/EC and 2010/31/EC) for the integration of SEC technologies [43]. These include establishing and expounding the minimum standards for building performance, the introduction of energy certification, and defining Net Zero Energy Building (NZEB) [44]. Smart buildings are considered living organisms that utilise automated processes to deliver more precise and useful information for augmenting the building's operational energy performance and reduce environmental impacts. Within the buildings domain, all the SEC projects highlight the need for smart building refurbishment as the primary strategy to improve building energy performance and improve indoor thermal comfort. Other significant approaches include:

- Building energy management strategies such as intelligent control and smart building monitoring for analysing occupants energy needs and consumption to alter their behaviour to maximise their efficiency automatically;

- Scaling-up investment in home energy efficiency;

- Building integrated renewable energy sources such as multi-technological systems, e.g., solar thermal and photovoltaic in roofs or facades, geothermal energy, and small biomass boilers to cover and reduce building energy requirements (electrical and thermal loads);

- Smart and energy efficient appliances and lighting systems to increase energy efficiency and reduce electricity cost;

- High-performance new "green" buildings;

- Passive solar design; and

- Building material technologies.

Akin to buildings, road transportation, both passenger and freight, has experienced an upward trend in GHG emission, accounting for 35\% in overall GHG emissions [42]. However, given the impetus to reduce transport emissions to $60 \%$ by 2050, new business models stimulated by disruptive smart transportation technologies and sharing economy are central to SEC projects. Although there is considerable variation in the scope and complexity of the projects' expanded mobility ecosystem, $82 \%$ of the SEC project has implemented transportation solutions centred around the following main areas:

- Travel demand management strategies such as car and bike e-sharing system, carpooling, and e-community;

- Smart fueling/charging infrastructure, such as recharge points, renewable storage, and recycling old batteries;

- Clean fuel vehicles such as hybrid fuels and hydrogen buses;

- Electric mobility including e-bikes, e-cars, e-buses, and e-cargo (e-logistics) bikes; and

- Advanced transport management systems such as traffic control system.

Today, the EU imports approximately $53 \%$ of the energy it consumes, which increases its dependency and vulnerability to external shocks and disruptions [45]. Furthermore, many European cities have ageing energy infrastructures that are inadequately interlinked. Consequently, modernisation of energy infrastructure network and diversification of energy mix are crucial for the EU to assimilate its energy market and meet its energy and climate goals. However, as a result, the EU has taken a hard-headed approach to transformation and optimisation of its energy system, with significant emphasis placed on improving energy security and diversification of the fuel mix. This is because technologies and interventions in the energy sector form the nucleus of smart and sustainable cities $[23,46]$. All the SEC projects examined promote smart energy system integrated solutions in a different spatial context to balance energy supply and demand. Through demonstration 
projects, the employment of smart interconnected energy network has the potential to mitigate the uncertainties associated with centralisation. Some of the leading SEC solutions that support collaborative environment include:

- Smart district heating and cooling systems;

- Smart and sustainable public street lighting system (e.g., light-emitting diodes, solar sensors);

- On and offsite renewable energy sources (e.g., offsite-smart hydropower plants, wind turbines, new-to-surface geothermal energy, and onsite-solar photovoltaic and solar thermal);

- Deployment of smart grids and smart meters;

- Smart microgrids;

- Wasted energy and heat recovery;

- Storage technologies (smart 2nd life battery storage, 2nd life reuse of EV batteries, grid balancing/energy storage, and thermal and renewable energy storage; and

- $\quad$ Energy data management.

Creaking urban infrastructure restricts development by stifling local economic development opportunities. ICT and integrative infrastructure are essential to the decarbonisation process in cities and represent a long-term approach to augmenting infrastructure management. Considered as an integral component of the SEC projects concept, it incorporates complex urban systems and their operational requirements, encompassing the energy system, transportation and mobility, smart urban services, communication, waste, water, sanitation, and citizen engagement. ICTs and integrative infrastructure help, among other things, to improve energy efficiency, decouple low carbon economy, and help reduce carbon footprints, by providing information to reduce energy consumption and augment economic growth. This can make a positive impact in all contexts on the affordability of energy and restructuring through innovation and behaviour change, process efficiencies, and change in other sectors, as well as create new employment opportunities. The most cross-cutting ICT and integrated infrastructure solutions implemented in the SEC demonstration cities are

- Open data, open energy, and visualisation platforms;

- Integrated data managing, monitoring, and reporting;

- Strategic urban planning support such as air quality sensors and monitoring, traffic sensors, smart grids, and street lights (smart lamp post) providing public Wi-Fi connectivity;

- Tools for community insight and engagement such as a website for developers, mobile applications for citizens, and participatory city modelling using geodata;

- Smart urban resilience development platform;

- Municipal informatisation plan;

- Smart waste collection optimisation;

- Digital skills and education; and

- Green Data Centre.

Co-Benefits of SEC Domains of Interventions Based on Sustainability Dimensions

The discourse on co-benefits or multiple benefits and their integration into sustainability are not only relevant in the context of SEC projects but also instrumental in the promotion of holistic urban development. The successful execution of SEC projects results in considerable co-benefits for individuals, communities, and society as a whole [27], which supports new development processes, market response, control and monitoring systems for behavioural change, human and technological resources, and public engagement. A co-benefit is any socio-economic, environmental, and positive governance effect attained from the implementation of a project and exceeds the primary goal, regardless whether intentional or not [28,47,48]. With this, "co-benefits are often subject to uncertainty and depend on, among others local circumstances and implementing practices" [49]. They are 
an embodiment of innovative technological strategies and regulatory and institutional policies, which encapsulate a diversity of short and long-term mutually prodigious societal values [50]. As seen in Table 4, implementing SEC solutions within the four primary domains of interventions will result in 29 sustainability co-benefits [51-54], which are seen as essential pillars of the broader energy and climate objectives, as well as improving the European countries socio-economic competitiveness. The quadruple pillars of sustainability are a powerful tool with which to categorise the interdependencies of the many technological and other strategic pathways that can have considerably different impacts on other endpoints.

\subsection{Implementing Principle}

Implementation is the process whereby strategies and plans are converted or transformed into actions to accomplish strategic objectives [55]. Effective implementation of action plans is a decisive component in the sustainable urban development process [55,56]. Notwithstanding this, despite the elaborate system of planning, and different commitments to an integrated urban agenda for sustainable urban development (e.g., climate and energy planning), there is scant normative literature on the "how" of sustainability. This has led to barriers to the implementation of projects [31] and largely unimplemented plans, especially in developing countries [57].

Table 4. In-depth assessment of the interconnectivity between the co-benefits and the planning components of SEC projects.

\begin{tabular}{|c|c|c|c|c|c|}
\hline \multirow{2}{*}{$\begin{array}{l}\text { Sustainability } \\
\text { Dimension }\end{array}$} & \multirow{2}{*}{ Co-Benefits } & \multicolumn{4}{|c|}{ Main Domains of Implementation } \\
\hline & & Buildings & $\begin{array}{l}\text { Transport } \\
\text { \& Mobility }\end{array}$ & $\begin{array}{l}\text { Energy \& } \\
\text { Technology }\end{array}$ & $\begin{array}{l}\text { ICT \& Integrated } \\
\text { Infrastructure }\end{array}$ \\
\hline \multirow{8}{*}{ Environmental (8) } & Reduced GHG emission & $\sqrt{ }$ & $\sqrt{ }$ & $\sqrt{ }$ & $\sqrt{ }$ \\
\hline & Increased energy efficiency and conservation & $\sqrt{ }$ & $\sqrt{ }$ & $\sqrt{ }$ & $\sqrt{ }$ \\
\hline & Increased renewable energy deployment & $\sqrt{ }$ & $\sqrt{ }$ & $\sqrt{ }$ & $\sqrt{ }$ \\
\hline & Reduced energy use & $\sqrt{ }$ & $\sqrt{ }$ & $\sqrt{ }$ & $\sqrt{ }$ \\
\hline & Optimised resource management & $\sqrt{ }$ & & $\sqrt{ }$ & $\sqrt{ }$ \\
\hline & More sustainable transport & & $\sqrt{ }$ & $\sqrt{ }$ & $\sqrt{ }$ \\
\hline & Reduced congestion and traffic safety & & $\sqrt{ }$ & & $\sqrt{ }$ \\
\hline & Improved ambient and indoor air quality & $\sqrt{ }$ & $\sqrt{ }$ & $\sqrt{ }$ & $\sqrt{ }$ \\
\hline \multirow{11}{*}{ Economical (11) } & \multirow{11}{*}{$\begin{array}{l}\text { Urban regeneration and economic growth } \\
\text { Improved energy system reliability } \\
\text { Improved energy security } \\
\text { Reduced energy cost/prices } \\
\text { Increased disposable income } \\
\text { Increased asset/property value } \\
\text { Increased access to energy services } \\
\text { Increased job creation } \\
\text { Increased finance and investment } \\
\text { Improved efficiency *, productivity, and } \\
\text { competitiveness } \\
\text { Increased technology and innovation }\end{array}$} & $\sqrt{ }$ & $\sqrt{ }$ & $\sqrt{ }$ & $\sqrt{ }$ \\
\hline & & $\sqrt{ }$ & $\sqrt{ }$ & $\sqrt{ }$ & $\sqrt{ }$ \\
\hline & & & $\sqrt{ }$ & $\sqrt{ }$ & \\
\hline & & $\sqrt{ }$ & $\sqrt{ }$ & & $\sqrt{ }$ \\
\hline & & $\sqrt{ }$ & & $\sqrt{ }$ & \\
\hline & & $\sqrt{ }$ & & $\sqrt{ }$ & $\sqrt{ }$ \\
\hline & & $\sqrt{ }$ & & $\sqrt{ }$ & $\sqrt{ }$ \\
\hline & & $\sqrt{ }$ & $\sqrt{ }$ & $\sqrt{ }$ & $\sqrt{ }$ \\
\hline & & $\sqrt{ }$ & $\sqrt{ }$ & $\sqrt{ }$ & $\sqrt{ }$ \\
\hline & & $\sqrt{ }$ & & $\sqrt{ }$ & $\sqrt{ }$ \\
\hline & & $\sqrt{ }$ & $\sqrt{ }$ & $\sqrt{ }$ & $\sqrt{ }$ \\
\hline \multirow{8}{*}{ Social (8) } & \multirow{8}{*}{$\begin{array}{l}\text { Increased citizen engagement } \\
\text { Increased public awareness and education } \\
\text { Enhanced access to urban mobility } \\
\text { Low-cost mobility } \\
\text { Access to ICT-better connectivity } \\
\text { Improved health and quality of life } \\
\text { Reduced fuel poverty } \\
\text { Enhancement of neighbourhood identity and } \\
\text { territorial attractiveness }\end{array}$} & $\sqrt{ }$ & $\sqrt{ }$ & $\sqrt{ }$ & $\sqrt{ }$ \\
\hline & & $\sqrt{ }$ & $\sqrt{ }$ & $\sqrt{ }$ & $\sqrt{ }$ \\
\hline & & & $\sqrt{ }$ & & $\sqrt{ }$ \\
\hline & & & $\sqrt{ }$ & & $\sqrt{ }$ \\
\hline & & $\sqrt{ }$ & $\sqrt{ }$ & & $\sqrt{ }$ \\
\hline & & $\sqrt{ }$ & $\sqrt{ }$ & $\sqrt{ }$ & $\sqrt{ }$ \\
\hline & & $\sqrt{ }$ & & $\sqrt{ }$ & $\sqrt{ }$ \\
\hline & & $\sqrt{ }$ & $\sqrt{ }$ & & $\sqrt{ }$ \\
\hline \multirow{2}{*}{ Governance (2) } & Innovation in processes and decision making & $\sqrt{ }$ & $\sqrt{ }$ & $\sqrt{ }$ & $\sqrt{ }$ \\
\hline & Improved multi-level relationships & $\sqrt{ }$ & $\sqrt{ }$ & $\sqrt{ }$ & $\sqrt{ }$ \\
\hline
\end{tabular}

* Efficiency-cities, business, and citizens.

Implementing the SEC solutions is the most crucial phase of the transformation process. Therefore, from a detailed review of the literature on sustainable urban planning project implementation $[25,26,55,58]$, and the vertical guidelines established in the SIP [25], we developed a compacted implementation framework consisting of eleven components, as presented in Figure 5. In general, the comprehensive implementation of SEC projects in all their dimensions necessitates 
planning mechanisms, governance, funding, monitoring, evaluation, context, and phasing to respond consistently and successfully to present and potential challenges. We found that almost all the implementation components had adequate coverage in SEC projects.

Planning mechanisms are the technical policies, guidelines, and legal and regulatory instruments that guide the development of SEC projects. From Table 5, planning mechanisms constitute 23\% of all the aspects of the implementation of the SEC projects. New policy tools and guidelines, for example, to guide building retrofits, stakeholder interventions, and transportation and mobility solutions have been incorporated in the SEC projects. Principally, because SEC projects emphasise upscaling, replication, and documentation of processes, the creation of toolbox and guidelines is used to provide learning resources for "follower cities". SEC learning resources are used to facilitate seamless integration of planning and design activities for these cities. Examples of these resources and tools include stakeholder analysis, district energy master plan, process model, PEST analysis, social monitoring guide, integrated project delivery, building information modelling, life cycle analysis, online energy atlas, integrated ICT decision support system platform, SWOT analysis, gamification, smart city energy assessment framework, geospatial urban energy information and support systems and databases, strategic implementation plan, 3D visualisation and model, taxonomy matrix, semantic technologies, automated feedbacks, participative management model, and impact assessment.

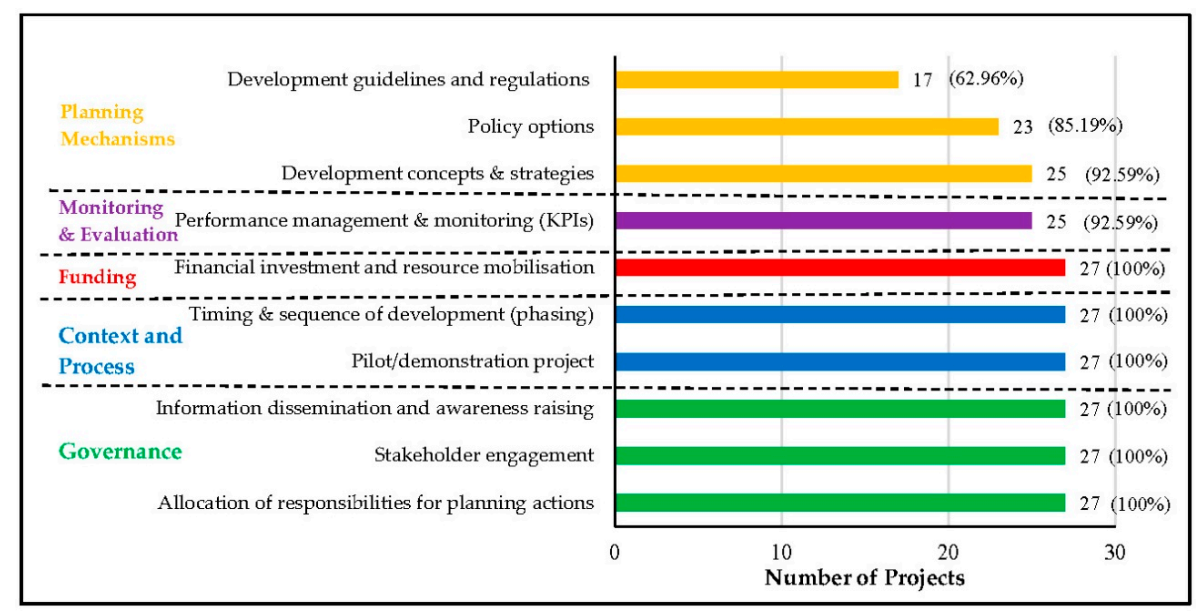

Figure 5. Approaches to SEC project implementation through institutional sustainability dimensions.

The genuine success of SEC projects hinges on the appropriate governance structure [59]. This is to some extent reflected in the results of this study, because relative to all the implementing dimensions, the dimension of governance was more prominent, constituting approximately $39 \%$ of the implementing dimensions (see Table 5). Embedded in SEC is a governance structure designed to incorporate political commitment and urban management, and the allocation of responsibilities for planning actions, stakeholder engagement, information dissemination, capacity building, and awareness raising [60]. We found that establishing political commitment from the municipal government is vital to the seamless integration of SEC solutions into different domains, as it provides the connection between citizens and the technical project partners [40,61]. During the implementation phase, integrated strategies and plans, as well as horizontal inter-departmental coordination and communication, exist, with roles and responsibilities allocated to project teams and municipal agencies. For stakeholder engagement and awareness, some of the common strategies utilised included one-to-one meetings, peer-to-peer knowledge exchange network and workshops, training, online webinars, creating learning networks, study tours, an online knowledge database, seminars, and questionnaires.

A comprehensive implementation framework requires integrated financial resources for the successful implementation of SEC solutions [59,62]. The project cost depends on the level of 
intervention, model, and ability to execute. Substantial financial resources, beyond the EU funding for SEC demonstration projects, will be required for the upscaling of the existing models. To this end, municipal government can integrate smart city projects in their annual budget, as well as leverage alternative funding options such as the European Structural Investment Funds (ESIF), European Investment Bank (EIB), European Fund for Strategic Investment (EFSI), and the European Bank for Reconstruction and Development (EBRD). Within the SEC projects analysed, a key implementation component that received considerable attention is the development and application of new business models, which are used to attract financing and investment. Innovative business model approaches are those that catalyse partnerships and financial options to accelerate improvements in the primary domains of intervention, as well as stimulate a market response. The new business models included subsidies for retrofit and incentives for transport shift, product-service-system, new revenue models, and new financial schemes based on public-private partnership (PPP).

Table 5. Relative proportions of the aspects of implementation in the SEC projects.

\begin{tabular}{clll}
\hline Category & \multicolumn{1}{c}{ Implementing Aspect } & $\begin{array}{c}\text { Relative Proportion } \\
\text { of Aspect }\end{array}$ & $\begin{array}{c}\text { Relative Proportion of } \\
\text { Implementing Category }\end{array}$ \\
\hline \multirow{3}{*}{ Planning Mechanisms } & Development guidelines and regulations & $0.061(6.1 \%)$ & $0.082(8.2 \%)$ \\
& $\begin{array}{l}\text { Policy options } \\
\text { Development concepts and strategies }\end{array}$ & $0.090(9.0 \%)$ & $0.233(23.3 \%)$ \\
\hline Monitoring and Evaluation & Performance management and monitoring (KPIs) & $0.090(9.0 \%)$ & $0.090(9.0 \%)$ \\
\hline Funding & Financial investment and resource mobilization & $0.090(9.0 \%)$ & $0.097(9.7 \%)$ \\
\hline \multirow{2}{*}{ Context and Process } & Pilot/demonstration project & $0.097(9.7 \%)$ & $0.194(19.4 \%)$ \\
\hline \multirow{2}{*}{ Governance (Institutional, } & Timing and sequence of development (phasing) & $0.097(9.7 \%)$ & \\
communication, and & Authorization and political commitment & $0.097(9.7 \%)$ & \\
participatory) & Allocation of responsibilities for planning actions & $0.097(9.7 \%)$ & $0.097(9.7 \%)$ \\
\hline
\end{tabular}

Monitoring and evaluation are synergistic processes and management tools that provide systematic information for tracking the planning and implementation progress of SEC project activities, and the impact of policy measures against pre-set targets and broader objectives. Transforming objectives into performance necessitates appropriate key performance indicator (KPIs). SEC projects monitoring and evaluating activities are most effective if conducted at the beginning, during, and after implementation of intervention measures. This is because they provide a critical guide to project stakeholders, which allows timely identification of gaps and successes to readjust the performance of SEC innovative technologies and solutions to meet the desired targets. Numerous management systems and initiatives for SEC development are implemented in Europe. Examples are the CONCERTO Technical Monitoring Guideline, the EUROCITIES framework and its Citykeys Horizon 2020 project [63], and the EU SCIS. For example, the Citykeys project developed a results evaluation system to address horizontal activities such as performance monitoring of smart cities project during and after the implementation of smart city solutions. The framework is organised in a comprehensive, triple-bottom-line sustainability structure, which encompasses five core thematic areas: people, planet, prosperity, governance, and propagation.

Context and phasing refer to pilot and demonstration projects and phasing of development. The SEC projects are characterised by high-level of pilot and demonstration (initial demonstration and large-scale) projects, which are used to test and develop new SEC technologies using experimentation zones, testbeds, and living labs, for commercial, city-wide roll-out. Given that the funding period is specified, the successful implementation of the SEC plan depends on certain elements being delivered at crucial stages, which include an indication of the time horizon envisaged for the project. This is to ensure that specific interventions and processes are developed in a logical and coordinated manner in the interest of the proper planning and sustainable development of the area. 


\subsection{Equity}

Equity is indispensable to achieving sustainability [6] and has been considered an essential issue for climate change decision-making [35]. Just as SEC cannot only be about advancing technologic solutions, sustainable development cannot only be about economic growth and environmental imperatives. As a result, comprehensive analysis of smart-sustainability development literature in Europe and America by Martin et al., 2018 [64], revealed that procedural and social equity principles could play an essential role in "unlocking the nexus of smart-sustainability of urban development".

\subsubsection{Procedural Equity}

The planning and development of SEC projects should ensure the intrinsic assimilation of procedural equity. Procedural equity holds that SEC projects should be based on normative judgment aligned with democracy, participatory governance, and a regulatory system in which stakeholder engagement is a central tenant in the overall decision-making when developing or implementing sustainability policies and programs (of regeneration) [36]. Effectively implementing projects, on-going engagement, and capacity building and collaboration will not only enable stakeholders to make informed decisions but also improve project outcomes at a local level by limiting project risks and failures. Intrinsic to the development of the SEC concept is the inclusion of stakeholders at the conceptualisation, planning, implementation, and monitoring and evaluation phases of the projects. Within this context, procedural equity should not be confined to legalistic and bureaucratic processes, for establishing and enforcing obligations and rights, but should embrace more extensive authentic processes of institutionalising equity that is integrated into the planning framework over several gamuts of scales.

Stakeholders are individuals or groups who have an interest in and are impacted by the success or failure of a project [9]. All-SEC projects are developed based on bottom-up collaboration within the triple helix [9] of internal (decision-makers, experts-universities and research institutes, and the private sector/industry), external (end-users), and lateral (utilities, community groups, financial institutions, and investors). From Figure 6, all the projects involved the participation of the internal stakeholders, and the majority $(85 \%)$ also featured in end-user involvement. The contributions of the internal stakeholders were relatively dominant $(57.0 \%)$ in the projects, followed by the lateral $(26.8 \%)$ and external stakeholders' involvements (16.2\%) (see Table 6). This suggests that the involvement of relevant stakeholders plays a leading role in the effective implementation of SEC projects. To guide the development of SEC projects, stakeholder structures have been developed through cooperation between international consortiums of technical partners and different local project stakeholders in demonstration sites. Each project stakeholder structure is tailor-made to respond to the local conditions and the complexity of policy interventions. The internationality of SEC projects means that stakeholders are usually of diverse socio-economic and cultural background, which adds complexity to the engagement process. At a local level, complexities exist due to the interdependencies between stakeholders who have a large variety of roles and interests, which have to be aligned with project objectives [65]. Notwithstanding this, the consortium of experts has been maximised to leverage integration between multiple disciplines, economic and social experiences, data sets, aspirations, views, and impacts.

Table 6. Relative proportions of stakeholder engagements in SEC projects.

\begin{tabular}{cccc}
\hline Stakeholders & Sub-Stakeholders & $\begin{array}{c}\text { Relative Weight of } \\
\text { Engagement }\end{array}$ & $\begin{array}{c}\text { Relative Weight of } \\
\text { Stakeholder Engagement }\end{array}$ \\
\hline \multirow{2}{*}{ Lateral stakeholders } & Financial institutions and investors & $0.051(5.1 \%)$ & $0.275(27.5 \%)$ \\
& Community groups & $0.137(13.7 \%)$ & $0.087(8.7 \%)$ \\
\hline External stakeholders & Utilities & $0.159(15.9 \%)$ & $0.159(15.9 \%)$ \\
\hline \multirow{2}{*}{ Internal stakeholders } & End users & $0.188(18.8 \%)$ & $0.188(18.8 \%)$ \\
& Private sector & $0.188(18.8 \%)$ & \\
\hline
\end{tabular}




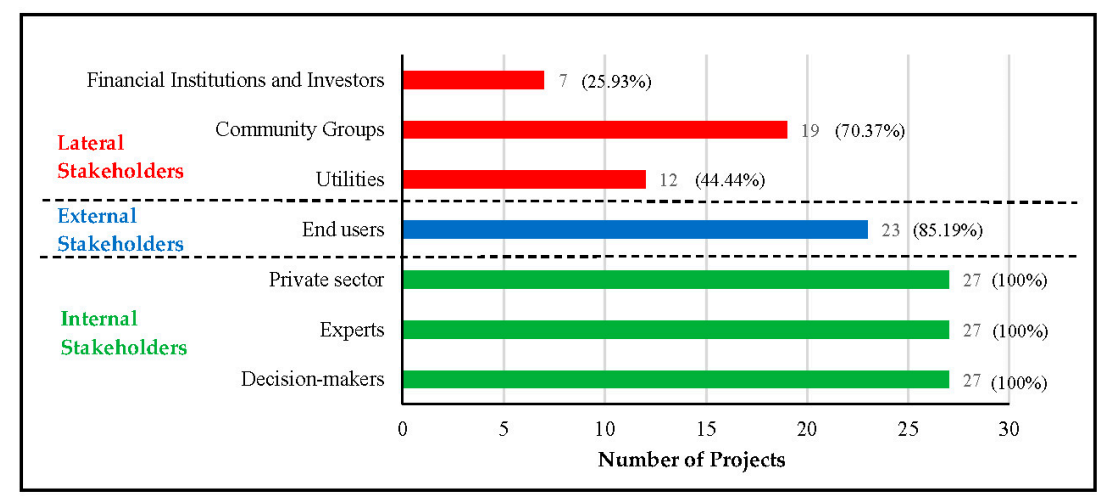

Figure 6. The primary stakeholders involved in SEC projects.

\subsubsection{Intra-Generational Equity}

Intra-generational equity can be attained when SEC projects, programs, and policies result in the fair consideration or distribution of economic and social benefits and resources between individuals of the same generation, and distribution of cost for environmental protection [36,66-70]. Within this context, the understanding of contemporary socio-economic and environmental benefits in the context of decent quality of life, healthy indoor and outdoor environment, and accessibility to corresponding physical and social infrastructures and services is fundamental to the continued sustainable urban development of all segments of a community, with prioritisation of those in greatest need [36,71-73]. The concept of intra-generational equity epitomises a broad spectrum of socio-spatial inclusion considerations, which have been interwoven into SEC projects. These include, among others, tackling fuel poverty and improving indoor comfort (for cold homes); improving well-being, reducing energy costs; equal access to broadband connectivity; equal platforms for participation and decision-making; provision of, and improvement in, social housing and low-income private dwellings; accessibility to mobility and low mobility cost; and data platforms and living labs to enhance public participatory governance, for example, tackling the complexities associated with fuel poverty is one of the fundamental tenets of SEC projects. This is because between 50 and 125 million European citizens cannot heat their homes adequately at an affordable cost and have inadequate insulation standards, especially the member states in the Central, Southern, and Eastern countries $[74,75]$. Although there is lack of commonality in the definition of the concept of fuel poverty, the fundamental understanding related to the concept in some jurisdictions such as the United Kingdom is that $10 \%$ of income is spent on maintaining adequate heating and cooling regime [76]. As a result, using smart energy data and associated solutions (e.g., domestic energy retrofits and weatherization) of buildings (public social housing and low-income residential dwelling) are effective strategies for reducing significant social impacts (e.g., social exclusion) and health impacts (e.g., mental disability, excess winter deaths, and ill-health) that will affect the vulnerable population and those unable to afford to make energy efficient refurbishment.

\subsubsection{Inter-Generational Equity}

As one of the cornerstones of sustainability, inter-generational equity argues for parity and fairness in generational or intertemporal consumption and utilisation of resources $[67,68,77]$. Time horizons as an element of urban sustainability planning help to guide future orientation, and the implementation of measures and pathways to achieve the desired objectives. Simply put, planning in its formal sense implies having the power to guide the future development of an area in the long term. However, the future oriented-ness of planning has been one of the contentious phenomena in planning theory and practice. Consequently, a normative policy shift from short-term to long-term time horizon will enable the futurity of the benefits of the development projects. Even though there is uncertainty in predicting futurity, establishing reference points for achieving targets allows for a conditional 
time horizon for future orientations [6]. Given the need to align planning and project results towards sustainability and climate targets, SEC projects have established specific long-term goals (e.g., 2030, 2050) as quantitative benchmark targets and baseline timelines with intermediate targets (e.g., EU 20-20-20 climate and energy objectives). SEC projects have fixed 3 to the 5-year timelines, although the co-benefits (inter-generational equity) to be achieved by their implementation transcend the long-term time horizon (two or more generations). As a result, this reduces the generational burden (e.g., cost of retrofit associated with carbon lock-in from urban infrastructure and environmental mitigation, and increased environmental resource protection through the utilisation of renewable energy). Therefore, such burden on future generations will be avoided.

\subsection{Scalability and Replicability}

SEC projects demonstrate the feasibility of transferring innovative solutions and knowledge. Scalability and replicability are two quintessentially endogenous principles that embody the characteristics of sustainability [78] and are embedded as core objectives of SEC projects. Scalability refers to the capacity of the urban system to facilitate the growth in demand or expansion for the implementation of SEC project solutions. Scalability is necessary for sustainability, as the various solutions of SEC projects are developed, tested, and validated at demonstration or pilot level, and subsequently diffused locally at a larger-scale [79]. In this way, the city will benefit from the scalable implementation of sustainability strategies and technologies. In the meantime, the replication of a form of scalability, which incorporates international transferability of the components the SEC projects, can be duplicated in other geographical locations. These are vital objectives in establishing the "pioneer-follower" city relationship business model that has been adopted by the EIP-SCC, as they reduce barriers to implementation in follower cities [80]. According to [16,79], although there is a proliferation of SEC projects, many are unable to transcend beyond the demonstration/pilot phase to create broader multi-benefits. This is attributed to the complexity of urban systems, financing, technology transfer, feasibility, and demand response. As a result, the authors of $[78,80]$ suggested essential technical, economic, stakeholder, and regulatory factors that underpin the successful scalability and replicability of any urban development projects.

We assessed the SEC projects based on the scalar placements of central domains, and the results are shown in Figure 7. Although several SEC projects are geared towards holistic smart urban development, the projects relating to energy-efficient retrofit of buildings are usually at the several district demonstration sites or building scales. The individual scale impacts consumer choice and behaviour in influencing consumption patterns [81]. However, transportation solutions and city-wide roll-out of ICT platforms to improve urban services are occurring throughout the city. After successful implementation of these demonstration projects, a municipal government can implement such best practices throughout the city. Consequently, this will trigger a broader coverage of co-benefits.

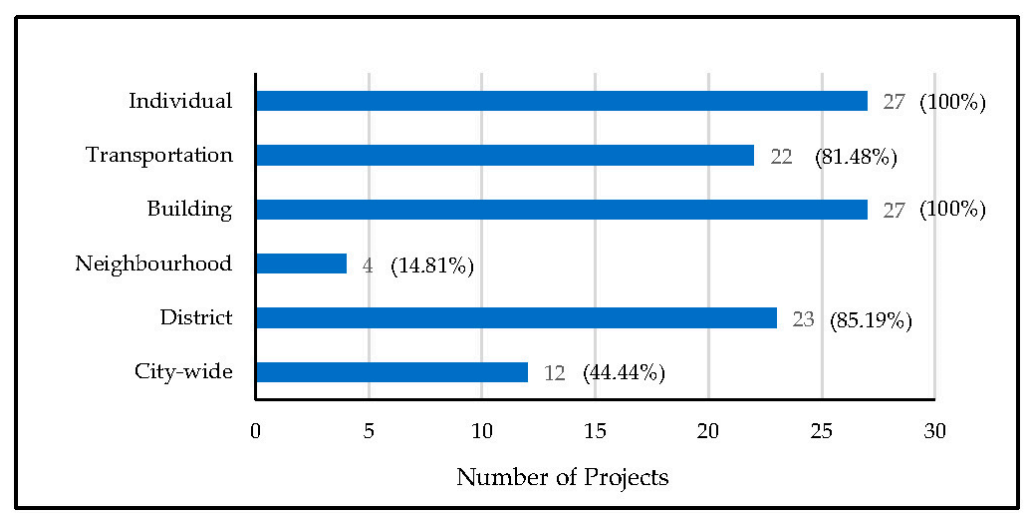

Figure 7. Scales of implementation of SEC projects. 


\section{Case Study: SINFONIA Project in Bolzano, Italy}

Bolzano is a small-sized city $\left(53 \mathrm{~km}^{2}\right)$ situated in northern Italy and is the capital and largest city in the provincial state of South Tyrol (see Figure 8). The city has a population of approximately 106,000 residents and supports a diversity of socio-economic, socio-spatial, administrative, and political functions that provide the impetus for the sustainability and energy goals. Seeking to become a model SEC for Italy, the city has established bold energy and climate change targets to reduce GHG emission by $20 \%$ by 2020 , and by $40 \%$ by 2030 , using the figures of 2010 as the baseline [82]. These targets are geared towards its commitment to the Covenant of Mayors Initiative (COM), to which the city became a signatory in 2009 [82].

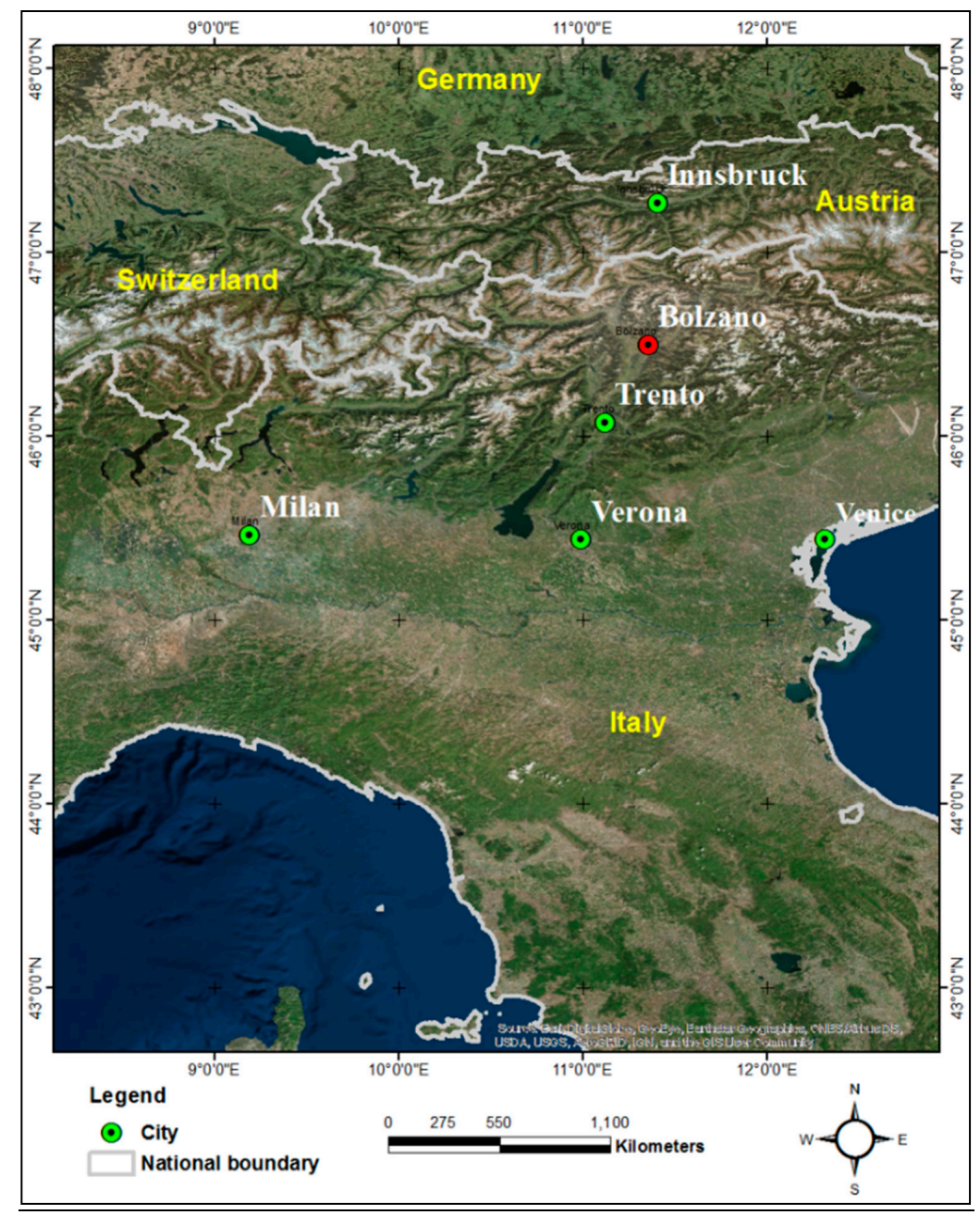

Figure 8. Location of Bolzano within the broader context of South Tyrol, Italy.

Considering its strategic geographical location, there is a more profound urge to transform the entire urban system into a best practice for sustainable urban development for small to medium size cities in the alpine regions. This ongoing transformation is perceived through the creation and implementation of local development initiatives, in transportation and mobility, climate and energy planning, land use planning, building construction, and several EU projects that incorporate energy-efficient buildings and smart and sustainable mobility and engagement (see Table 7). These initiatives will continue to stimulate economic growth and diversification, drive proactive deployment of sustainable and low carbon development actions, improve people's quality of life, and create seamless frameworks for integrating multi-level stakeholder participation. 
Table 7. Existing local strategic frameworks and projects are supporting sustainable urban development through smart cities, urban energy planning, and urban planning.

\begin{tabular}{|c|c|}
\hline Initiatives & Comments \\
\hline Existing Green Mobility Initiatives & $\begin{array}{l}\text { - } \quad \text { Establishes a multimodal transport system. } \\
\text { - } \quad \text { cycling infrastructure. } \\
\text { - } \quad \text { Pedestrianisation of the urban centre. } \\
\text { - } \quad \text { Electric mobility is central to achieving smart and sustainable alpine mobility. } \\
\text { - Introduces an electronic ticketing system on its public transport network. } \\
\text { Incentivises mechanism to reduce transport cost per kilometre travelled. }\end{array}$ \\
\hline Bolzano Master Plan, 2010 & $\begin{array}{l}\text { Forecasts socio-economic growth, infrastructure requirements, and other } \\
\text { drivers of sustainable transition in the city. } \\
\text { Promotes energy sustainability through the deployment of technologies and } \\
\text { strategies in buildings and mobility to improve the quality of life of residents. }\end{array}$ \\
\hline Bolzano Mobility Plan, 2020 & $\begin{array}{l}\text { - Promoted "sustainability" as the central strategic objective towards achieving } \\
\text { the goal of being a model region for sustainable alpine mobility. } \\
\text { - Aims for a well-structured public transportation network providing a high } \\
\text { level of accessibility. } \\
\text { - Based on the integration and optimisation of different modes of transport, and } \\
\text { the deployment of smart and ecological friendly technological modes. } \\
\text { Encourages transportation demand management strategies. }\end{array}$ \\
\hline South Tyrol Energy Climate Strategy, 2050 & $\begin{array}{l}\text { - Elaborates a strategic guide to elaborate future scenario of energy } \\
\text { development in the city towards achieving } 90 \% \text { * renewable energy by } 2050 . \\
\text { Establishes the right institutional and regulatory governance, participation } \\
\text { and awareness, and research and international cooperation. }\end{array}$ \\
\hline Casaclima Nature, 2008 & $\begin{array}{l}\text { - Promotes energy-efficient and sustainable buildings through the certification } \\
\text { of building energy performance. } \\
\text { - } \quad \text { Conducts specialised training, public education, and awareness campaigns }\end{array}$ \\
\hline Volume Bonus Program & $\begin{array}{l}\text { - A financial instrument that increases (reward) building volume for } \\
\text { energy retrofit }\end{array}$ \\
\hline Energy Planning Office in the Municipality & $\begin{array}{l}\text { - The city has established an energy planning office (and energy manager) that } \\
\text { coordinates the implementation of the its sustainable energy planning } \\
\text { strategies through collaboration and awareness raising with various agencies } \\
\text { such as CasaClima Agency, IDM Alto Adige, and other local stakeholders. }\end{array}$ \\
\hline Sustainable Energy Action Plan (SEAP), 2014 & $\begin{array}{l}\text { - Establishes GHG reduction target of } 20 \% \text { by } 2020 \text { compared to } 2010 \text { levels. } \\
\text { - Aims at environmental sustainability, mitigating climate change impacts, and } \\
\text { improving the quality of life of residents. } \\
\text { - Proposes } 28 \text { necessary actions to achieve these targets, under seven sectors. }\end{array}$ \\
\hline \multicolumn{2}{|r|}{ European Projects } \\
\hline $\mathrm{CHIC}$ & - Deploys five $12-\mathrm{m}$ buses and hydrogen and fuel cell technologies centre. \\
\hline HyFIVE & $\begin{array}{l}\text { - Deploys Fuel Cell Electric Vehicles (FCEVs) and develops hydrogen } \\
\text { refuelling infrastructure. }\end{array}$ \\
\hline NewBusFuel & $\begin{array}{l}\text { - Develops planning guidelines and technical solutions for the development of } \\
\text { refuelling infrastructures for entire fuel cell bus fleets. }\end{array}$ \\
\hline SINFONIA & $\begin{array}{l}\text { - Aims to integrate large-scale sustainability targets in city planning through } \\
\text { the transformation of parts of the city into a smart energy city. }\end{array}$ \\
\hline $\begin{array}{l}\text { COmmonENERGY, 3ENcult, BRICKER } \\
\text { EPOURBAN }\end{array}$ & $\begin{array}{l}\text { - These projects aim at energy efficiency retrofit in buildings and stakeholder } \\
\text { engagement to increase the performance of buildings. }\end{array}$ \\
\hline REZIPE, 2010 & $\begin{array}{l}\text { - } \quad \text { Seeks to reduce GHG gas emissions from transport in urban areas. } \\
\text { - } \quad \text { Deploys through the provision of technical policy tools. } \\
\text { - Promotes the use of electric bikes and provides solar panel charging stations. }\end{array}$ \\
\hline INTEGREEN, 2015 & $\begin{array}{l}\text { - Develops and deploys innovative and collaborative approach to ICT for } \\
\text { sustainable and smart mobility for traffic/environmental data management. } \\
\text { Improves logistics in the city during critical peak situation, dynamic traffic } \\
\text { data, eco-friendly policies support, and devises an open and web-based ITS } \\
\text { platform to provide business-to-consumers services. }\end{array}$ \\
\hline
\end{tabular}


The SINFONIA "Smart INitiative of cities Fully cOmmitted to iNvest In Advanced large-scale energy solutions" project is a five-year (2014-2019) smart city urban development project co-funded under the European Union's Seventh framework programme (FP7) [28]. The project seeks to implement and transform small and medium-sized cities using an integrated approach to smart energy cities [83] (see Figure 9). Implementation is occurring through three interconnected strands: the energy refurbishment of buildings at the district scale, large-scale energy solution through district heating and cooling, and the provision of smart points, which offers a wide array of urban services to citizens [27]. The project's success hinges on the symbiotic relationship between pilot cities Bolzano, Italy and Innsbruck, Austria. Both cities collaborate towards the implementation of strategies to attain energy savings and renewable energy targets in the demonstration districts.

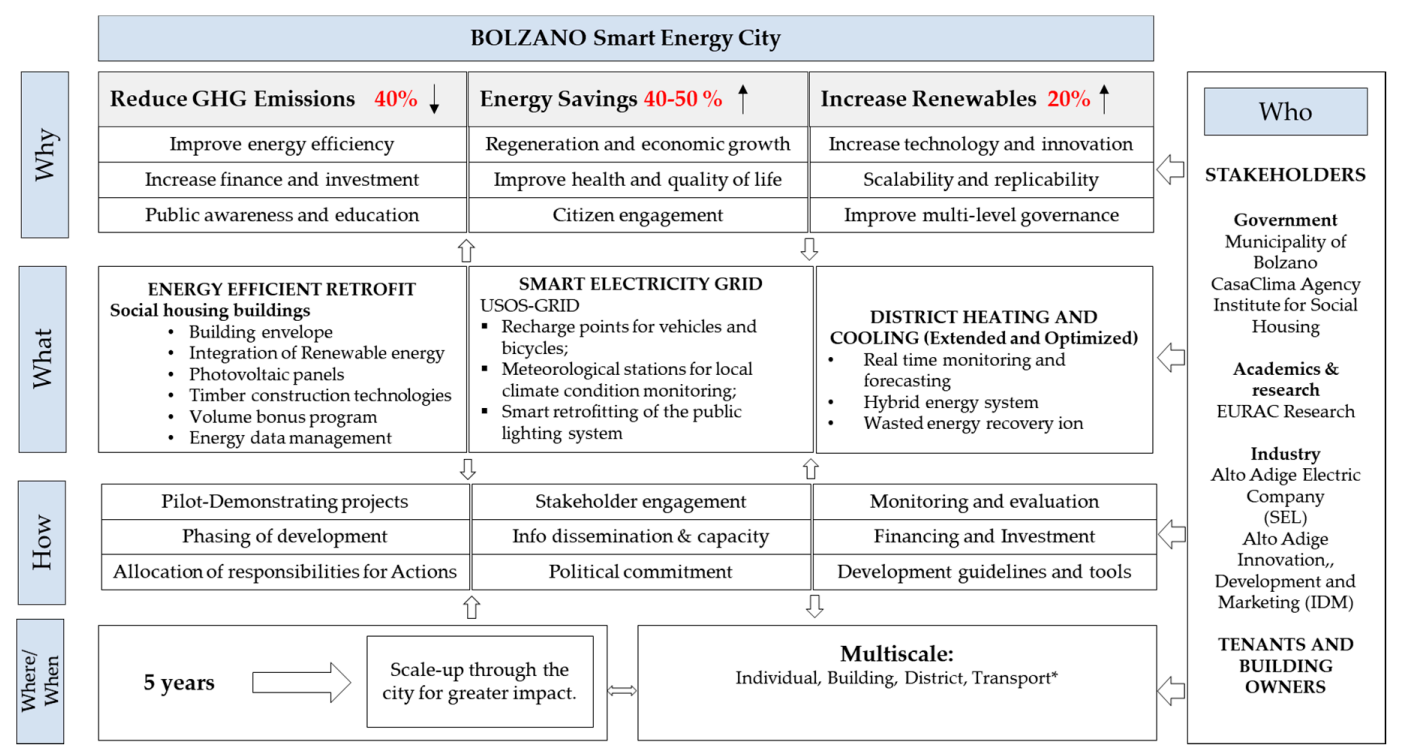

Figure 9. Summary of SEC-integrated approach in Bolzano.

The integration principle of sustainability is represented in the SINFONIA project through the core objectives and the main planning domains of interventions. Striving to become one of the most energy-efficient cities in Europe for environmental sustainability and smart integrated development, five "core" objectives are identified with the hope of aligning the goal of the project with localising and European targets, as well as enhancing the social, economic, and governance dichotomy in the city. These include the robust cooperation with Bolzano and Innsbruck, which enhances transnational collaboration; the ambitious reduction targets (such as $40-50 \%$ primary energy savings, intensifying the proportion of renewable energy by $20 \%$, both cutting GHG emission by $40 \%$ ), which will have multiple co-benefits and form the core of environmental sustainability; and the innovative, scalable, and replicable integrated ICT infrastructure solutions that will provide a stepping stone for low carbon city economy [84]. In the planning domains grounds, the transformation to an SEC in Bolzano centred around three fundamental strands: buildings, energy system, and ICT and integrated infrastructures [27,84]. This specific direction reflects the spectrum necessary to improve sustainability dimensions at various scales. Within a broader context, approximately $70 \%$ of the buildings within Bolzano are over 25 years [84], which according to the SEAP [82] is responsible for $82.53 \%$ of energy consumption and GHG emissions in the city. From 2005, the city has made attempts to retrofit existing buildings within the municipality, through the "cubature bonus" programs [85]. SINFONIA intends to enhance this process through the large-scale energy efficiency retrofit of $451\left(31,000 \mathrm{~m}^{2}\right)$ local social housing, constructed between the 1950s and 1970s, by 2020 [85]. This will enable these residential buildings to attain a higher level of energy performances. Regarding the energy domain, the projects seek to expand and optimise the district heating and cooling network to reduce GHG 
emissions. These will be through the installation of renewable energy and other clean energy sources. The integration of ICT into the building refurbishment process entails the use of sensors to monitor energy consumption by tenants and externally through the electricity grid. The third domain comprises the harmonisation of ICT and integrated infrastructure to enhance the quality of services to citizens. The installation of the innovative USOS-grid services/architecture comprises 150 smart points in specific neighbourhoods in the city. These will provide urban services such as recharge stations for electric bicycles and vehicles, public WI-FI connectivity, sensors for detecting the weather, monitoring of air quality and traffic, and real-time monitoring and forecasting of peak loads and energy demand (demand and supply) [84]. Furthermore, smart retrofit of public lighting infrastructure using LED will be undertaken, which uses less energy and significantly reduces the cost of keeping the streets illuminated. Overall, the co-benefits to be attained from executing projects in these three domains can unlock economic growth and spur social equity and environmental management and governance. Some of these co-benefits include improvement of the quality of life, reduction in energy poverty, increase in energy security, creating employment opportunities, reversing negative environmental externalities (such as air pollution), and increasing access to urban services through the deployment of ICT solutions, among others, [84].

The implementing principle of the SINFONIA project is characterised in governance, planning mechanisms, monitoring and evaluation, context and process, and financing. Pioneer cities, such as Bolzano, which are transitioning on an SEC sustainable urban development trajectory, require not only radical technological transformation but also multilevel and multidimensional governance structures that consist of strengthening institutional realm, responsibilities, citizen engagement and social inclusion, collaboration, information dissemination for awareness. These components ensure that implementation activities are aligned and coordinated to gain buy-in from all stakeholders and reconcile social acceptance of SEC interventions, e.g., inconveniences caused by retrofit and installation of smart meters [86]. As a result, the foreseen objectives of the project are being achieved, because local acceptance for the demonstration strategies is high [87]. Within this context, stakeholder engagement forms a critical component of the project planning and implementation process on two distinct levels [87]. On the first level, higher level, face-to-face communication meetings between internal partners are undertaken to ensure that individual stakes such as "learning through the exchange, economic benefits through innovation and sustainability" and roles are identified and delineated. This kind of group building process, although intensive and time-consuming, can bridge the gap between conflicting stakeholders and enhance social relationships [86]. On the other level, the relationship between the internal and external tenants (and building owners) requires information exchange and, to a lesser extent, consultation. Stakeholder engagement and awareness tools that have been utilised including meetings, questionnaires, minicourses, and journals are the primary communication approaches [87]. As it relates to funding, the project uses EU funding ( $€ 27 \mathrm{~m}$ of the total $€ 42 \mathrm{~m}$ is funded under the FP7 framework) to augment public and public funding resources. Furthermore, successfully executing the SEC project to maximise potential socio-economic benefits requires collaboration and cooperation with the private/economic sector, political directorate, and end-users. To stimulate market response and business development, a local stakeholder panel was initiated to facilitate the seamless collection and utilisation of data about behavioural change [87]. This panel consisted of core project partners, industry, decision-makers, and residential representatives. The planning mechanisms in the SINFONIA project represent various conceptual, technical, and methodological guides and tools, many of which are available on digital platforms, to support planning and implementation of the projects and form part of the city transformation. These planning tools include stakeholder analysis for evaluating stakes and decision impact on stakeholders, deCision suppoRt fOr distriCt refurbishment (CROCUS) tool to select a refurbishment plan, SWOT tool to test smart city solution [88], district templates, good practices for stakeholders' participation, guidelines to build an energy baseline scenario, and good practice district stimulator to refine local master plans for SEC transition [89]. Further corresponding to the legal and 
institutional frameworks in the city, the project seeks to maximise building energy performance by utilising the casaclima nature certification system, as well as the volume bonus program. Monitoring and evaluation for measuring the success of the projects are being undertaken using KPIs [90]. The KPIs help to characterise the energy performance of a district and assess the impact of the refurbishments. Using methodological standards established in the CONCERTO Technical Monitoring Guideline, the KPIs reflect technical, social, economic, and environmental principles of sustainability to estimate progress specifically towards the SEC interventions.

As it relates to equity, procedural equity has been conceptualised from the planning phase and helps to ensure strong participatory governance alignment, while intra-generational and inter-generational equity will be attained as co-benefits through the implementation of solutions. As it pertains to intra-generational equity, smart retrofit of buildings and building-integrated renewable energy system will result in increased thermal comfort, tackling differential energy burdens, reduced energy poverty, reduced energy costs, accessibility to broadband connectivity, and new job opportunities, as well refurbishment of social housing to reach energy use standards and curtail energy poverty. The participatory planning process is seen as a set of intra-generational tools that is used to enhance governance, and tenants' engagement and awareness. During the post-construction phase, digital innovation including participatory and data platforms are designed to ensure that structural problems can be reconciled by behavioural change. However, there is current debate and trepidation regarding the co-benefits of transformation and the substantially anticipated increase in rental cost. Inter-generational equity of the project entails the protection of resources through the utilisation of renewable energy sources, conservation of natural resources through retrofit instead of reconstruction, and utilisation of timber construction technologies. For example, long-term energy efficiency and renewable energy building retrofit have the potential to avoid further carbon lock-in and thus reduce GHG emissions in cities. Although the timeline of the project is five years, the co-benefits to be realised from its implementation surpass this period. The transition to an SEC city model through the retrofitting of buildings and uptake of sustainable forms of energy will, therefore, enable the city to achieve its benefits and co-benefits over a long-term time horizon. Undertaking a stakeholder analysis to identify and understand their roles and stakes is a critical component in the success of the project implementation in Bolzano and comprises the procedural equity component of sustainability. This is because the explicit allocation of responsibilities and demarcation of stakes, respectively, enable effective collaboration and management of stakeholder and project complexities such as competing interests and overlap in administrative and technical capabilities. The central consortium of internal stakeholders who are responsible for the implementation of the project in Bolzano is characterised by three fundamental categories $[84,87]$ : government, research institute, and industry. They were selected based on their direct influence and potential involvement in the project activities, such as high level of commitment, deep collaboration, markets development, and political visions [87]. The government consortium consists of the municipality of Bolzano, the Institute for Social Housing (IPES), and the CasaClima Agency (ACC). The municipality is the most central player for the development of the smart city concept in the city, given its political and administrative influence. Researchers from the Institute of Renewable Energy at Eurac Research are the scientific and technical consultants. The Institute coordinates project planning and provide support to the municipality in the planning and rehabilitation, and define rehabilitation criteria. Industry partners consist of the Alto Adige Electric Company (SEL) and the Alto Adige Innovation, Development, and Marketing (IDM), which intervene in district heating network and the provision of business support services, respectively. The tenants and building owners in the demonstration areas acts as external stakeholders, as they are the final end-users and beneficiaries of the services enabled by the implementation of smart solutions (see Table 8). This diverse group of consortia in the city ensures that multidisciplinary and multidimensional complexities/perspectives are incorporated from a broad spectrum of society.

Finally, being one of the central emphases of SINFONIA project, a substantial part of the project is geared towards scalability and replicability to ensure transferability of project solutions and 
tools. District scale interventions ensure that scalable prototypes and tools can use to guide early adopter cities such as Sevilla-Spain, La Rochelle-France, Rosenheim-Germany, Borås-Sweden, and Paphos-Cyprus to implement their district-scale redevelopment strategies.

Table 8. Assessment of SINFONIA project in Bolzano against endogenous sustainability factors.

\begin{tabular}{|c|c|c|c|}
\hline Sustainability Principle & Factors & Criteria & Coverage \\
\hline \multirow[t]{2}{*}{ Integration } & $\begin{array}{l}\text { Objectives, planning dimensions, } \\
\text { and their co-benefits }\end{array}$ & $\begin{array}{c}\text { Social } \\
\text { Economic } \\
\text { Environmental } \\
\text { Governance }\end{array}$ & $\begin{array}{l}\sqrt{ } \\
\mathrm{O} \\
\sqrt{ } \\
\sqrt{ }\end{array}$ \\
\hline & \multicolumn{2}{|c|}{ Interconnectivity } & $\sqrt{ }$ \\
\hline Implementation & & $\begin{array}{c}\text { Planning mechanism } \\
\text { Monitoring and evaluation } \\
\text { Funding } \\
\text { Context and phasing } \\
\text { Institutional, communication, and participatory }\end{array}$ & $\begin{array}{l}\sqrt{ } \\
\sqrt{ } \\
\sqrt{ } \\
\sqrt{ } \\
\sqrt{ }\end{array}$ \\
\hline \multirow[t]{4}{*}{ Equity } & Procedural & Stakeholders integration & $\sqrt{ }$ \\
\hline & \multicolumn{2}{|c|}{ Intra-generational } & $\sqrt{ }$ \\
\hline & \multicolumn{2}{|c|}{ Intergenerational } & $\sqrt{ }$ \\
\hline & \multicolumn{2}{|c|}{ Scalability and replicability } & $\sqrt{ }$ \\
\hline
\end{tabular}

NB: $(\sqrt{ })$ Full coverage: and $(O)$ Partially coverage:.

\section{Conclusions, Limitations, and Future Studies}

This research is deemed a preliminary contribution to the development of empirical research to attain fundamental insight into the SEC components, through the lens of past and current projects. SEC has emerged as a central urban development model that seeks to decarbonise cities, increase human health and quality of life, and ensure energy security. As a result, this study was designed to analyse the success of SEC projects at enhancing the sustainable development of urban settlements. This paper is considered a first attempt to provide a comprehensive sustainability assessment of SEC projects in the EU consortia. In the first part of this paper, we articulated the theoretical conceptualisation of smart cities, briefly outlining the international context of the concept and European Union sustainability and digitisation policies that underpin the development of the strategy. After presenting this context, we introduced the analytical framework that was used to analyse the 27 SEC European projects, as well as the case of SINFONIA in Bolzano, Italy. This was based on the Kipling conceptual framework integrated into the four sustainability principles: integration, implementation, equity (intragenerational, inter-generational, and procedural), and scalability and replicability.

The results of this study disclosed that core objectives of the projects are strategically aligned with the EU climate and energy targets, and other policy planning guidelines. Furthermore, we found that the four main planning domains provide for the integration principle of sustainable development including buildings, transport and mobility, ICT and integrated infrastructure, and energy technologies. These will catalyse social, environmental, economic, and governance-related co-benefits. Theoretically, the implementing principles are well articulated throughout SEC projects and include good governance structure, planning mechanisms, finance and resource mobilisation, context and processing, and monitoring and evaluation. Although intra-generational and inter-generational equity is not readily discernible and articulated in project planning domains, they exist as co-benefits that are attained from project implementation. As a result, it would be optimal if these equity issues were fully outlined in the early stages and quantified after the implementation of the projects. Also, it was shown that SEC technological solutions alone cannot bring about sustainability, but procedural equity incorporating active stakeholder engagement and awareness processes in the planning and implementation phases is necessary to ensure maximum buy-in and acceptance. We also found 
that accelerating the implementation of projects at demonstration sites and wide-spread scale-up will be required to fully achieve the long-term decarbonization goals. Hence, after the projects are completed, the onus will lie on the local authorities to develop financial mechanisms for scale-up activities. Scalability and replicability principles are the cornerstone of SEC projects in the European context. Although several socio-economic and political factors impact the level of transferability, the different prototype tools provide working benchmarks for follower cities in their development effort. Further, we analysed the SINFONIA project in Bolzano, Italy against the content framework of the other SEC projects to determine if, in reality, the current components of the Bolzano project are achievable. Our study indicated that the principles of sustainability are articulated in all components of the project. However, to attain higher targets of energy efficiency performance for buildings in the city, there is the need to scale-up technological solutions. To achieve this, finance, investment, and resource mobilisation through public-private partnership (PPP) and marketing of project outcomes are needed to trigger commercialisation. Although working under different regulatory environments, there exists a unique stakeholder arrangement and collaboration, which facilitates the implementation of strategies. Finally, it was assessed if the current model of SEC projects could be replicated in other international regions. Based on our findings, the EU consortia of SEC projects through the EIP-SCC provides a structured approach for European cities to transition to a sustainable and low-carbon society. The demonstration and pilot projects through various SEC solution prototypes, tools, and methodology can provide an example for international cities focusing on Brownfield and Greenfield development. Notwithstanding, SEC projects should not be seen as a panacea to sustainable urbanisation, as European countries have different socio-economic environments, climatic conditions, regulatory systems, and financial arrangements. Therefore, developing countries, which are going through rapid urbanisation and modernisation processes, can, therefore, integrate SEC solutions into their urban planning and development process that align with the local conditions, at the outset.

Although an attempt is made to analyse a wide variety of SEC projects using the case of SINFONIA project in Bolzano, Italy, a more comprehensive sample is required including international projects in different geographical regions such as Asia, North America, and the global south. Furthermore, a general framework based on the $5 \mathrm{~W} 1 \mathrm{H}$ conceptual framework was used to garner data to be analysed for this study. However, a more rigorous scale weighing factors and the framework for indicator development is needed. Future study should seek to empirically analyse a larger sample of cities that have implemented SEC projects, using both European and international cases, to obtain a greater comparative analysis of the various components to understand the relationships between various geographical areas, socio-economic dynamics, human capital, and environmental and technological replicability. With the significance of energy in catalysing local and global sustainable development, further research is needed to identify and classify the various SEC solutions to provide best practices for other international cities looking to embrace the SEC framework. Furthermore, to ascertain more detailed results, a comprehensive indicator framework needs to be developed with scale weighting factors. However, future indicators can be categorised using the sustainability principles identified in this study. Further research is also needed to examine the procedural equity challenges such as stakes, the stages of involvement of tenants and landlords, social acceptance, and the level of participation.

Future research is also needed to assess the scalability and replicability of the completed pilot and demonstration projects. This will provide insights into the various socioeconomic, governance, and cultural dynamics that influence the successful adoption and implementation in other jurisdictions to ensure long-term sustainability.

Author Contributions: G.W.H. and D.V. conceptualised and identified projects and the case study. G.S. analysed data and co-wrote the paper. The paper was presented at the 2018 International Conference on Smart Cities and Urban Design (SCUD 2018) in Wuhan, China and was invited for the Special Issue for the same forum.

Funding: This research received no external funding 
Acknowledgments: We would like to thank the SEC experts in the EURAC research in Bolzano who provided guidance and technical support in the execution of this study, as well as the accommodation and facilitation during my (the corresponding author) stay in Bolzano during 2015-2016. The authors are grateful to the two anonymous reviewers for their helpful comments and suggestions regarding an earlier version of this paper.

Conflicts of Interest: The authors declare no conflict of interest.

\section{Abbreviations}

\begin{tabular}{ll} 
CORDIS & Community Research and Development Information Service \\
COM & Covenant of Mayors \\
CROCUS & deCision suppoRt fOr distriCt refurbishment \\
EBRD & European Bank for Reconstruction and Development \\
EC & European Commission \\
EEA & European Environmental Agency \\
EIB & European Investment Bank \\
EIP-SCC & European Innovation Partnership on Smart Cities and Communities \\
EFSI & European Fund for Strategic Investment \\
ESIF & European Structural Investment Funds \\
EU & European Union \\
ICT & Information and Communication Technologies \\
IDM & Innovation, Development and Marketing \\
GDC & Green Digital Charter \\
GHG & Greenhouse Gases \\
OIP & operational implementation plan \\
SEAP & Sustainable Energy Action Plan \\
SEC & Smart Energy City \\
SES & Smart Energy System \\
SET & Strategic Energy Technology \\
SCIS & Smart Cities Information System \\
SINFONIA & Smart INitiative of cities Fully cOmmitted to iNvest In Advanced large-scale energy solutions \\
SIP & Strategic Implementation Plan \\
& \\
\hline
\end{tabular}

\section{Appendix A}

Table A1. Smart energy city projects reviewed.

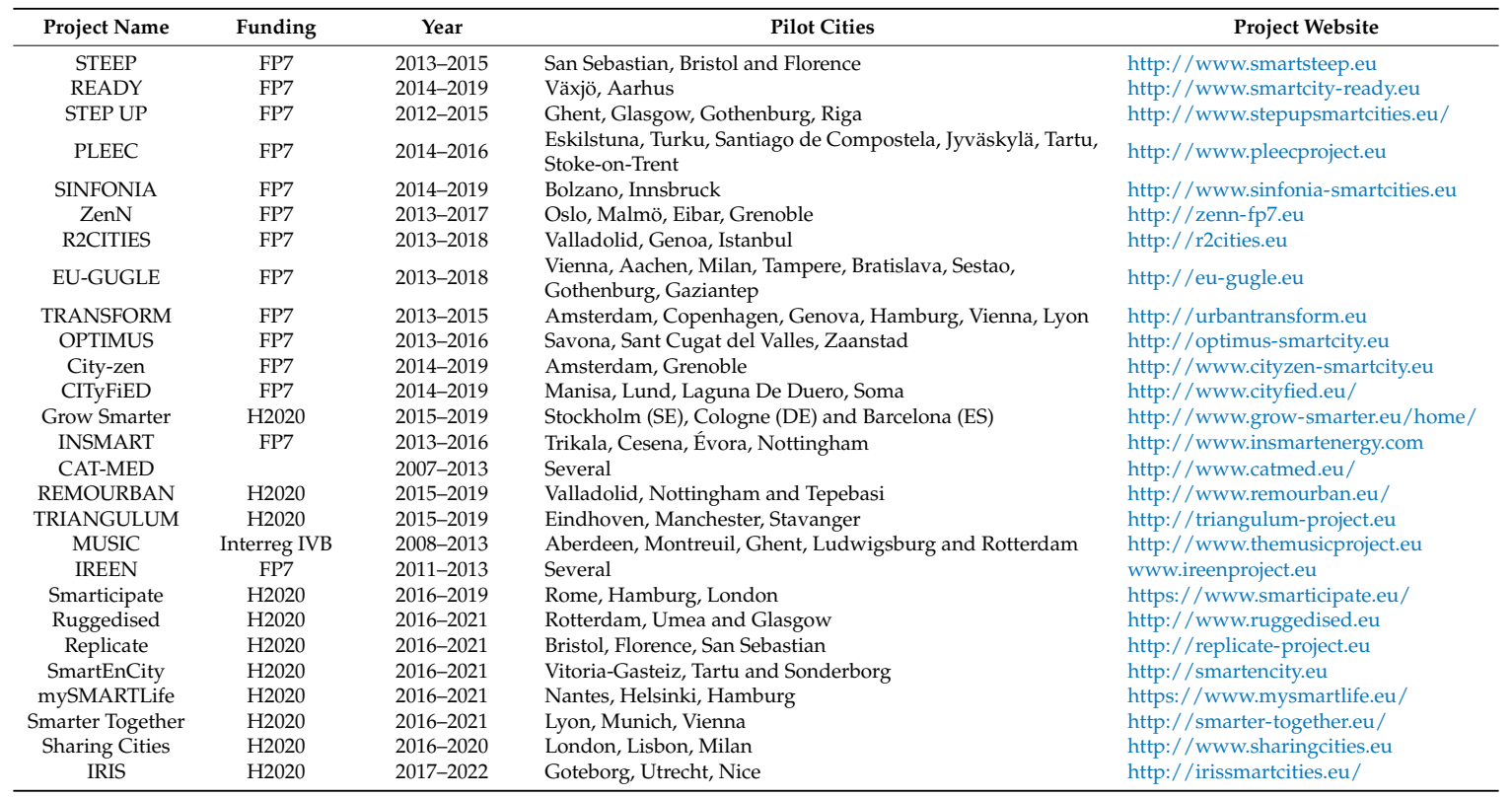




\section{References and Note}

1. EuroStat. Urban Europe-Statistics on Cities, Towns and Suburbs-Green Cities; EuroStat: Rue Alphonse Weicker, Luxembourg, 2016.

2. United Nations. World Urbanization Prospects: The 2014 Revision, Highlights (ST/ESA/SER.A/352); United Nations: New York, NY, USA, 2014.

3. European Commission, “Cities," Climate Action. Available online: https://ec.europa.eu/clima/policies / international/paris_protocol/cities_en (accessed on 24 April 2018).

4. Estevez, E.; Lopes, N.V.; Janowski, T. Smart Sustainable Cities. Reconnaissance Study; International Development Research Center: Ottawa, ON, Canada, 2016; pp. 1-330.

5. De Jong, M.; Joss, S.; Schraven, D.; Zhan, C.; Weijnen, M. Sustainable-smart-resilient-low carbon-eco-knowledge cities; Making sense of a multitude of concepts promoting sustainable urbanization. J. Clean. Prod. 2015, 109, 25-38. [CrossRef]

6. Sharifi, A.; Murayama, A. The Potential of 'CASBEE for Urban Development' for Delivering Sustainable Communities: A Case Study from the 'Koshigaya Lake Town' Planning Experience. J. Int. City Plan. 2012, 703-713. Available online: https:/ /www.researchgate.net/profile/Ayyoob_Sharifi/publication/259758150_ The_Potential_of_CASBEE_for_Urban_Development_for_Delivering_Sustainable_Communities_A_Case_ Study_from_the_Koshigaya_Lake_Town_Planning_Experience/links/0f31752da7f28895c7000000/ThePotential-of-CASBEE-for-Urban-Development-for-Delivering-Sustainable-Communities-A-Case-Studyfrom-the-Koshigaya-Lake-Town-Planning-Experience.pdf (accessed on 24 June 2018).

7. Doukas, H.; Marinakis, V.; Spiliotis, E.; Psarras, J. OPTIMUS decision support tools: Transforming multidisciplinary data to energy management action plans. In Proceedings of the 2016 7th International Conference on Information, Intelligence, Systems \& Applications (IISA), Chalkidiki, Greece, 13-15 July 2016; pp. 1-5.

8. Nielsen, S.P.; Amer, S.B.; Dtu, K.H. Definition of Smart Energy City and State of the Art of 6 Transform Cities Using Key Performance Indicators: Deliverable 1.2; Danish National Research Database: Copenhagen, Denmark, 2013.

9. Mosannenzadeh, F.; Bisello, A.; Vaccaro, R.; D'Alonzo, V.; Hunter, G.W.; Vettorato, D. Smart energy city development: A story told by urban planners. Cities 2017, 64, 54-65. [CrossRef]

10. EUROCITIES, Green Digital Charter, 2016. Available online: http://www.greendigitalcharter.eu/ (accessed on 7 June 2018).

11. National Institute of Urban Affairs. Exploratory Research on Smart Cities: Theory, Policy and Practice; National Institute of Urban Affairs: New Delhi, India, 2015.

12. Gil, O.; Zheng, T.C. Smart cities through the lenses of public policy: The case of Shanghai. Rev. Esp. Cienc. Polit. 2015, 1, 63-84.

13. Perez, F. Planning for a Strategic Guadalajara:Towards a Sustainable and Competitive Metropolis. FOCUS 10: Essays. 2014. Available online: https://pdfs.semanticscholar.org/0f2a/ 01b97ecd3a27ba76cd4fd3a24c671f227389.pdf?_ga=2.15125302.1444396967.1528496108-764292989. 1522225311 (accessed on 8 June 2018).

14. Mullins, P.D. The Ubiquitous-Eco-City of Songdo: An Urban Systems Perspective on South Korea 's Green City Approach. Urban Plan. 2017, 2, 4-12. [CrossRef]

15. Lee, S.E.; Braithwaite, P.; Leach, J.M.; Rogers, C.D.F. A comparison of energy systems in Birmingham, UK, with Masdar City, an embryonic city in Abu Dhabi Emirate. Renew. Sustain. Energy Rev. 2016, 65, 1299-1309. [CrossRef]

16. Van Winden, W.; van den Buuse, D. Smart City Pilot Projects: Exploring the Dimensions and Conditions of Scaling Up. J. Urban Technol. 2017, 24, 51-72. [CrossRef]

17. Morishita, N.; Heidenreich, M.; Hemmers, R.; Vankann, M.; Sahakari, T.; Vainio, T.; Pagliano, L.; Treberspurg, M.; Österreicher, D. EU-GUGLE: A Sustainable Renovation for Smarter Cities from a Pilot Project BT-Smart and Sustainable Planning for Cities and Regions: Results of SSPCR 2015; Bisello, A., Vettorato, D., Stephens, R., Elisei, P., Eds.; Springer International Publishing: Cham, Germany, 2017; pp. 353-382.

18. Manitiu, D.N.; Pedrini, G. Smart and Sustainable Cities in the European Union. An ex Ante Assessment of Environmental, Social, and Cultural Domains; IRIS: Louvain-la-Neuve, Belgium, 2015.

19. Kylili, A.; Fokaides, P.A. European smart cities: The role of zero energy buildings. Sustain. Cities Soc. 2015, 15, 86-95. [CrossRef] 
20. European Commission. Comunication from the Commission: A Roadmap for Moving to a Competitive Low Carbon Economy in 2050; European Commission: Brussels, Belgium, 2011.

21. European Commission. Roadmap to a Single European Transport Area-Towards a Competitive and Resource Efficient Transport System; European Commission: Brussels, Belgium, 2011.

22. European Commission. Energy Efficiency Plan 2011; European Commission: Brussels, Belgium, 2011.

23. European Commission. European Energy Security Strategy; European Commission: Brussels, Belgium, 2014.

24. European Commission. Towards an Integrated Strategic Energy Technology (SET) Plan: Accelerating the European Energy System Transformation; European Commission: Brussels, Belgium, 2015.

25. European Commission. European Innovation Partnership on Smart Cities and Communities Strategic Implementation Plan; European Commission: Brussels, Belgium, 2013.

26. European Commission. European Innovation Partnership on Smart Cities and Communities. Operation Implementation Plan; European Commission: Brussels, Belgium, 2014.

27. Bisello, A. Smart and Sustainable Projects at the Energy-District Level. How to Assess Them Based on the Co-Benefits Paradigm. Ph.D. Thesis, Università degli Studi di Padova, Padova, Italy, 2017.

28. Bisello, A.; Vettorato, D.; Stephens, R.; Elisei, P. Co-benefits of smart and sustainable energy district projects: An overview of economic assessment methodologies. In Proceedings of the International Conference on Smart and Sustainable Planning for Cities and Regions, Bolzano, Italy, 22-24 March 2017; pp. 127-164.

29. EIP SCC. Market Place Smart Cities and Communities Roadmap 2017 Supporting Action Clusters' Initiatives to Deliver Business Cases and Scale Them Up, 2017.

30. Basiri, M.; Azim, A.Z.; Farrokhi, M. Smart City Solution for Sustainable Urban Development. Eur. J. Sustain. Dev. 2017, 6, 71-84. [CrossRef]

31. Mosannenzadeh, F.; di Nucci, M.R.; Vettorato, D. Identifying and prioritizing barriers to implementation of smart energy city projects in Europe: An empirical approach. Energy Policy 2017, 105, 191-201. [CrossRef]

32. Mosannenzadeh, F.; Vettorato, D. Defining smart city. A conceptual framework based on keyword analysis. TeMA J. Land Use Mobil. Environ. 2014, 103-112. [CrossRef]

33. Jia, C.; Cai, Y.; Yu, Y.T.; Tse, T.H. $5 \mathrm{~W}+1 \mathrm{H}$ pattern: A perspective of systematic mapping studies and a case study on cloud software testing. J. Syst. Softw. 2016, 116, 206-219. [CrossRef]

34. Berelson, B. Content Analysis in Communication Research; Free Press: New York, NY, USA, 1952.

35. Pachauri, R.K.; Allen, M.R.; Barros, V.R.; Broome, J.; Cramer, W.; Christ, R.; Church, J.A.; Clarke, L.; Dahe, Q.; Dasgupta, P.; et al. Sustainable Development and Equity. In Climate Change 2014: Mitigation of Climate Change. Contribution of Working Group III to the Fifth Assessment Report of the Intergovernmental Panel on Climate Change; IPCC: Geneva, Switzerland, 2014.

36. Brown, K.; Corbera, E. Exploring equity and sustainable development in the new carbon economy. Clim. Policy 2003, 1, S41-S56. [CrossRef]

37. Randhawa, A.; Kumar, A. Exploring sustainability of smart development initiatives in India. Int. J. Sustain. Built Environ. 2017, 6, 701-710. [CrossRef]

38. Lopes, N.V. Smart governance: A key factor for smart cities implementation. In Proceedings of the 2017 IEEE International Conference on Smart Grid and Smart Cities (ICSGSC), Singapore, 23-26 July 2017; pp. 277-282.

39. Shukla, R. Models of Smart Governance. In Special Collection on eGovernment Innovations in India-ICEGOV'17; ACM: New York, NY, USA, 2017; pp. 82-87.

40. Castelnovo, W.; Misuraca, G.; Savoldelli, A. Smart Cities Governance: The Need for a Holistic Approach to Assessing Urban Participatory Policy Making. Soc. Sci. Comput. Rev. 2016, 34, 724-739. [CrossRef]

41. European Commission. European Innovation Partnership on Smart Cities and Communities: Operational Implementation Plan—First Public Draft; European Commission: Brussels, Belgium, 2013.

42. European Environment Agency. Key Trends and Drivers in Greenhouse Gas Emissions in the EU in 2015 and over the Past 25 Years; European Environment Agency: Copenhagen, Danmark, 2017; pp. 1-7.

43. European Commission. Directive 2009/28/EC on the promotion of the use of energy from renewable sources. Off. J. Eur. Union 2009, 140, 16-62.

44. European Commission. The Directive 2010/31/EU of the European Parliament and of the Council of 19 May 2010 on the energy performance of buildings. Off. J. Eur. Union 2010, 53, 1-6.

45. Lombardi, P.; Gruenig, M. Low-Carbon Energy Security from a European Perspective; Academic Press: Cambridge, MA, USA, 2016. 
46. Rademaekers, K.; van Nuffel, L.; Yearwood, J. EU Energy Independence, Security of Supply and Diversification of Sources. In EU Energy Independence, Security of Supply and Diversification of Sources; European Parliament Think Tank: London, UK, 2017.

47. Bisello, A.; Grilli, G.; Balest, J. Co-benefits of Smart and Sustainable Energy District Projects. In International Conference Smart and Sustainable Planning for Cities and Regions 2015; Eurac Research: Bozen, Italy, 2015.

48. International Energy Agency. Capturing the Multiple Benefits of Energy Efficiency; International Energy Agency: Paris, France, 2014.

49. The Intergovernmental Panel on Climate Change (IPCC). Climate Change 2014: Mitigation of Climate Change; Cambridge University Press: Cambridge, UK, 2014.

50. Casini, M. Green Technology for Smart Cities. IOP Conf. Series: Earth Environ. Sci. 2017, 83, 012014. [CrossRef]

51. Payne, J.; Weatherall, D.; Downy, F. Capturing the multiple benefits of energy efficiency in practice: The UK example. ECEE Summer Study Proc. 2015, 229-238. Available online: http:/ / www.energysavingtrust.org.uk/ sites/default/files/reports/1-424-15_Payne.pdf (accessed on 24 June 2018).

52. MacNaughton, P.; Cao, X.; Buonocore, J.; Cedeno-Laurent, J.; Spengler, J.; Bernstein, A.; Allen, J. Energy savings, emission reductions, and health co-benefits of the green building movement. J. Expo. Sci. Environ. Epidemiol. 2018, 8, 1-12.

53. Barker, T. Climate Change 2007: An Assessment of the Intergovernmental Panel on Climate Change. Change 2007, 446, 12-17.

54. Ürge-Vorsatz, D.; Novikova, A.; Sharmina, M. Counting good: Quantifying the co-benefits of improved efficiency in buildings. In Proceedings of the 2009 Summer Study, La Colle sur Loup, France, 1-6 June 2009; pp. 185-195.

55. Farthing, S.M. Local Land Use Plans and the Implementation of New Urban Development. Eur. Plan. Stud. 2001, 9, 223-242. [CrossRef]

56. UN-Habitat. Inclusive and Sustainable Urban Planning; UN-Habitat: Nairobi, Kenya, 2007.

57. Manyena, S.B. Non-implementation of development plans and participatory action research in Zimbabwe. Plan. Theory Pract. 2013, 14, 315-332. [CrossRef]

58. Laurian, L.; Day, M.; Backhurst, M.; Berke, P.; Ericksen, N.; Crawford, J.; Dixon, J.; Chapman, S. What drives plan implementation? Plans, planning agencies and developers. J. Environ. Plan. Manag. 2004, 47, 555-577. [CrossRef]

59. Tobergte, D.R.; Curtis, S. Smart Cities and Communities-European Innovation Partnership; BUILD UP: Brussels, Belgium, 2012.

60. European Commission. The Integrated Strategic Energy Technology (SET) Plan for Transforming the European Energy System through Innovation; European Commission: Brussels, Belgium, 2017.

61. Meijer, A.; Rodrı, M.P. Governing the smart city: A review of the literature on smart urban governance. Int. Rev. Adm. Sci. 2016, 82, 392-408. [CrossRef]

62. European Commission. Smart Cities Stakeholder Platform. Financing Models for Smart Cities; Europeaan Commission: Brussels, Belgium, 2013.

63. Huovila, A.; Seppä, I.P.; Airaksinen, M. Smart City Performance Measurement. In Proceedings of the 41st IAHS WORLD CONGRESS: Sustainability and Innovation for the Future, Albufeira, Algarve, Portugal, 13-16 September 2016; pp. 1-11.

64. Martin, C.J.; Evans, J.; Karvonen, A. Technological Forecasting \& Social Change Smart and sustainable? Five tensions in the visions and practices of the smart-sustainable city in Europe and North America. Technol. Forecast. Soc. Chang. 2018, 133, 269-278.

65. Nijman, H. Dynamic Roles in Smart City Development. Master's Thesis, University of Twente, Enschede, The Netherlands, 2014.

66. Horn, L.S. Intragenerational equity: A key concept in the United Nations Framework Convention on Climate Change. In Proceedings of the Australasian Law Teachers' Association, Perth, Australia, 23-26 September 2007.

67. Park, A. Equality in Sustainability: An Equality Scan of Local Government Sustainability Program; USDN Sustainability Directors Network: New York, NY, USA, 2014.

68. Vojnovic, I. Intergenerational and intragenerational equity requirements for sustainability. Environ. Conserv. 1995, 22, 223-228. [CrossRef] 
69. Ramlogan, R. Intragenerational Equity. In Sustainable Development; Brill: Leiden, The Netherlands, 2010; pp. 233-246.

70. Portes, J. Intergenerational and Intragenerational Equity. Natl. Inst. Econ. Rev. 2014, 227, 4-11. [CrossRef]

71. Rayner, S.; Malone, E.L. Climate change, poverty, and intragenerational equity: The national level. Int. J. Glob. Environ. Issues 2001, 1, 175-202. [CrossRef]

72. Haughton, G. Developing sustainable urban development models. Cities 1997, 14, 189-195. [CrossRef]

73. Haughton, G. Environmental Justice and the Sustainable City. J. Plan. Educ. Res. 1999, 18, 233-243. [CrossRef]

74. Maxim, A.; Mihai, C.; Apostoaie, C.-M.; Popescu, C.; Istrate, C.; Bostan, I. Implications and Measurement of Energy Poverty across the European Union. Sustainability 2016, 8, 483. [CrossRef]

75. Atanasiu, B.; Kontonasiou, E.; Mariottini, F. Alleviating Fuel Poverty in the EU: Investing in Home Renovation, A Sustainable and Inclusive Solution; Buildings Performance Institute Europe (BPIE): Brussels, Belgium, 2014.

76. Moore, R. Definitions of fuel poverty: Implications for policy. Energy Policy 2012, 49, 19-26. [CrossRef]

77. Summers, J.K.; Smith, L.M. The Role of Social and Intergenerational Equity in Making Changes in Human Well-Being Sustainable. Ambio 2014, 43, 718-728. [CrossRef] [PubMed]

78. May, K.; Vingerhoets, P.; Sigrist, L. Barriers regarding scalability and replicability of smart grid projects. In Proceedings of the 2015 12th International Conference on the European Energy Market (EEM), Lisbon, Portugal, 19-22 May 2015; pp. 1-5.

79. Van Winden, W. Smart city pilot projects: Scaling up or fading out?-Hogeschool van Amsterdam. In Proceedings of the Regional Studies Association Annual Conference in Austria, Graz, Austria, 3-6 April 2016; pp. 1-19.

80. Sigrist, L.; May, K.; Morch, A.; Verboven, P.; Vingerhoets, P.; Rouco, L. On scalability and replicability of smart grid projects-A case study. Energies 2016, 9, 195. [CrossRef]

81. Kullman, M.; Campillo, J.; Dahlquist, E.; Fertner, C.; Giffinger, R.; Grosse, J.; Groth, N.B.; Haindlmaier, G.; Kunnasvirta, A.; Strohmayer, F.; et al. Note: The PLEEC Project-Planning for Energy Efficient Cities. J. Settl. Spat. Plan. 2016, 5, 1-4.

82. Sparber, W.; Fedrizzi, R.; Avesani, S.; Exner, D.; Mahlknecht, H. Calcolo e Valutazione Delle Emissioni di $\mathrm{CO}_{2} e$ Definizione di Scenari di Riduzione Per la Città di Bolzano; European Academy of Bozen/Bolzano (EURAC): Bolzano, Italy, 2010.

83. Mosannenzadeh, F.; Bisello, A.; Diamantini, C.; Stellin, G.; Vettorato, D. A case-based learning methodology to predict barriers to implementation of smart and sustainable urban energy projects. Cities 2017, 60, 28-36. [CrossRef]

84. Vettorato, D. Empowering Transnational Seminar: Horizon 2020. In Proceedings of the Transnational Seminar, Athens, Greece, 4 April 2017; p. 60.

85. Nzengue, Y.; du Boishamon, A.; Laffont-Eloire, K.; Partenay, V.; Abdelouadoud, Y.; Zambelli, P.; D’Alonzo, V.; Vaccaro, R. Planning City Refurbishment: An Exploratory Study at District Scale How to move towards positive energy districts-Approach of the SINFONIA project. In Proceedings of the 2017 International Conference on Engineering, Technology and Innovation (ICE/ITMC), Madeira Island, Portugal, 27-29 June 2017; pp. 1394-1400.

86. Balest, J.; Vettorato, D. Social Acceptance of Energy Retrofit in Social Housing: Beyond the Technological Viewpoint. Green Energy and Technology; Springer: Berlin, Germany, 2018; pp. 167-177.

87. SINFONIA. Deliverable No 6.1.a: Site Specific Reports for Pilot City: Bolzano and Innsbruck; SINFONIA: Tokyo, Japan, 2014.

88. Simon, P.; Roberto, V.; Pietro, Z.; Farnaz, M.; Adriano. Deliverable 2.1 SWOT Analysis Report of the Refined Concept/Baseline: SINFONIA-'Smart INitiative of Cities Fully cOmmitted to iNvest in Advanced Large-Scaled Energy; SINFONIA: Tokyo, Japan, 2014.

89. SINFONIA. Good Practice District Stimulator: Refinement of Local Master Plans for Smart Energy Cities Transition: The Experience of Bolzano and Innsbruck; SINFONIA: Tokyo, Japan, 2016.

90. Kempe, M.; Gervind, P. Deliverable 5.1: Report on Measurement Plan and Data Acquisition System (Common Monitoring Methodology); Gothenburg, Sweden, 2015.

(C) 2018 by the authors. Licensee MDPI, Basel, Switzerland. This article is an open access article distributed under the terms and conditions of the Creative Commons Attribution (CC BY) license (http:/ / creativecommons.org/licenses/by/4.0/). 